\title{
Doença de Rustizky-Kahler
}

\author{
(myeloma)
}

\begin{abstract}
Resumo da these de doutoramento do Dr. Ernesto de Souza Campos preparador da cadeira de Histologia da Faculdade de Medicina e Cirurgia de São Paulo; approvada com grande distinç̧ão e louvor. premiada pela $S$. Medicina e Cirturgia de S. Paulo (Premio Dr. Sergio Meira).
\end{abstract}

$\mathrm{O}$ auctor começa o seu trabalho, determinando as differentes denominações que tem tido o myeloma multiplo que elle chama doença de Rutizky-Kahler. prestando assim homenagem ao autor (Rustizky) que, pela primeira vez, isolou esta entidade morbida em 1873 (Deutsch Zeitschr. f. Chirurgie.)

Faz em seguida um rapido historico e completa o 1.0 Capitulo da sua obra, resumindo os trabalhos publicados sobre o assumpto: Bence Jones (1848); Rustizky (1873); Arnold (1873); Buch (1873) ; Sudhoff (1873); Grawitz (1879); Nasse (1883); Runenberg (1883); Waldestein (1883); Zahn (1875); Marchand (1886); Coates (1891); Pertik (1888); Kahler (1889); Israel (1890); Stokiwis (1891); Kudrewetzky (1892); Wieland (1893); Odenit1s (1894); Herrick und Hectoen (1894); Spiegelbers (1894); Hammer (1894); Marckwald (1895); Dittrick (1896); Dubost (1897); Sussmann (1897); Ewald. (1897); Bozzolo (1897); Seegelken (1897); Rosin (1897) ; Parkes Weber (1898); Bradshaw (1898); Ellinger (1899); Baumgarten (1898); Askanazy (1899); Senator (1899); Buchstab und Schaposchnikow (1899); 'Winkler (1900); Sorge (1900); Funkestein (1900) D'Allocco (1900)' Flora (1900); Donetti (1901);: Hamburguer (1901); Wieland (1901); Veuturi (1901); Barr (1901); Mac Callum (1901); Blair (1901); Conti (1902); Bechtold (1902); Bell and Keenau (1902); Wright (1902); Jochmann und Schumm (1902); Bonardi (1903); Harbitz 1903); Michcli (1903); Saltikow (1903); Vignard et Gallavardin (1903); Abrikossoff (1903); Anders Boston (1903); Sternberg (1903); Bradshaw (1903); Dick (1904); Jellineck (1904); Zinninger (1904); Ribbert (1904); Meltzer (1904); Hoffmann (1904); Bruce et Lund (1904); Bertoye (1904); Austin (1904); Shelle und Herxheimer (1904); Sternberg (19,04); Weiss (1905); Mof fatt (1905); Wein (1905); Kalischer (1905); Collins (1905) ; Norris (1906); Nonner (1906); Menne (1906); Lubarsch (1906); Aschoff (1905); Helly (1906): Verebély (1906): Gluzinski u. Reichenstein (1906); Quackembo (1906); Degli Occhi (1907); Charles und Sanguinetti (1907); Umber u Hueter (1907); Brown (1907); Christian (1907); Permin (1907); Scarlini (1908); Schmidt (1908): Heyde (1908); Bessethagen (1908); Albert Herz (1908); Benda (1908); Beitzke (1908); Carl Hart (1909); Weber and Sednigham (1909); Pede (1909); Dialti (1910); Tschistowitsch u. Kollessnikoff (1909); Enochim u. Sabolotnou (1910); Berblinger (1910); Bevacqua (1910); Finker (1911); De Benzi (1911); Williand (1911); Conti (1911); Lunghetti (1911); Werd (1911); King; Simmonds (1912); Klebs Schmor1 (1912); Versé (1912); Kichensky (1912); Shennan (1913); Schutz (1913); Graves (1913); Mever (1913); Ueckorst1mer (1913); Warstat; Caporali; Hirschfeld (1914); Perry u. Pearce (1917); Haberfeld e Lordy (1917). 


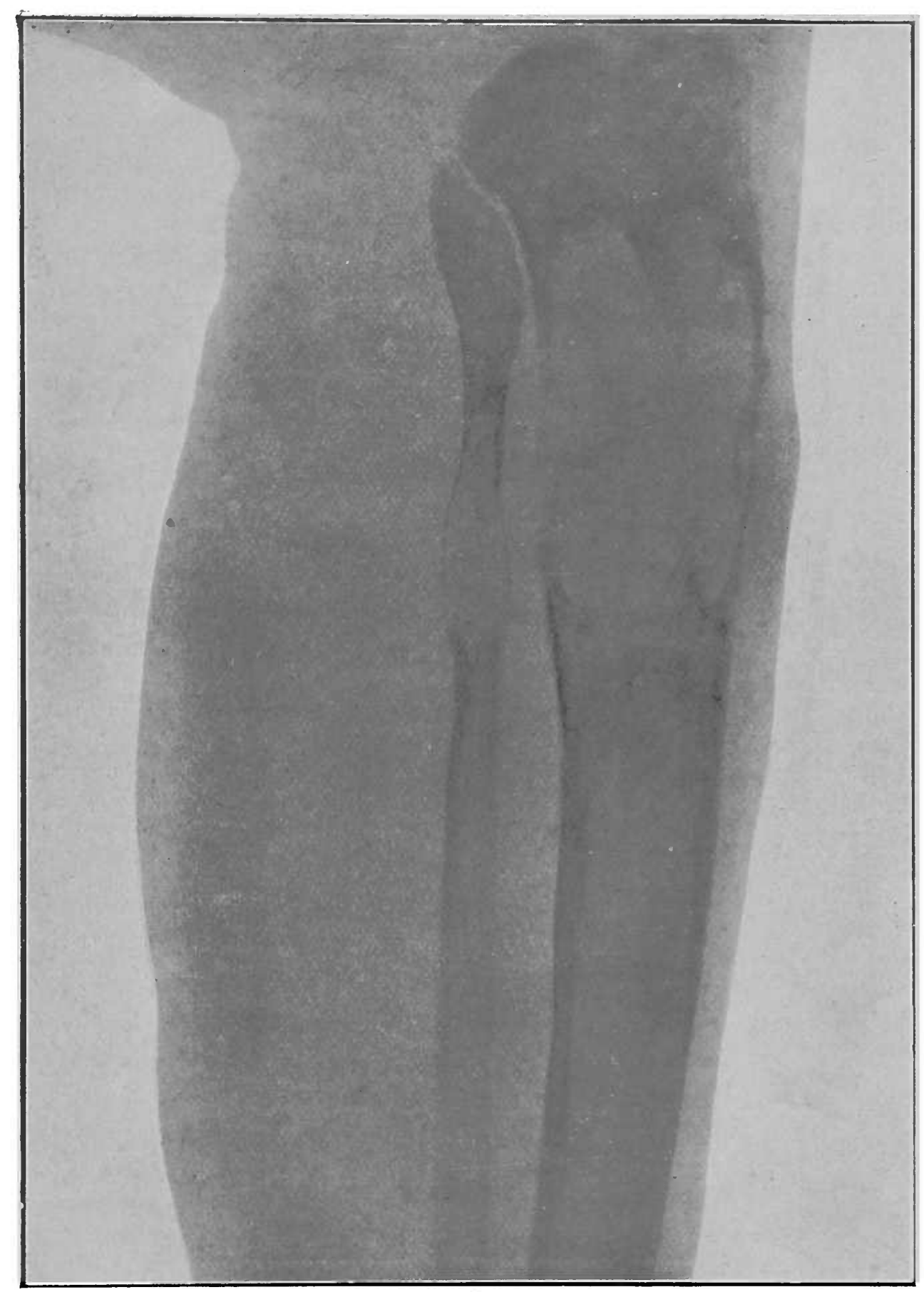

FIC. I

\section{Radiographia do terço superior da perna direita}

(a parte superior do espaço claro corresponde ao que está assignalado com a designação $m 4$ na FiG. V)

Observam-se dois grandes fócos myelomatosos na parte superior da tibia e do peroneo - produzindo a rarefacção ossea da substancia compacta - e a propagação do processo para a parte inferior dos mesmos ossos. Houve fractura expontanea no lugar correspondente a estes dois grandes fócos de myeloma. 



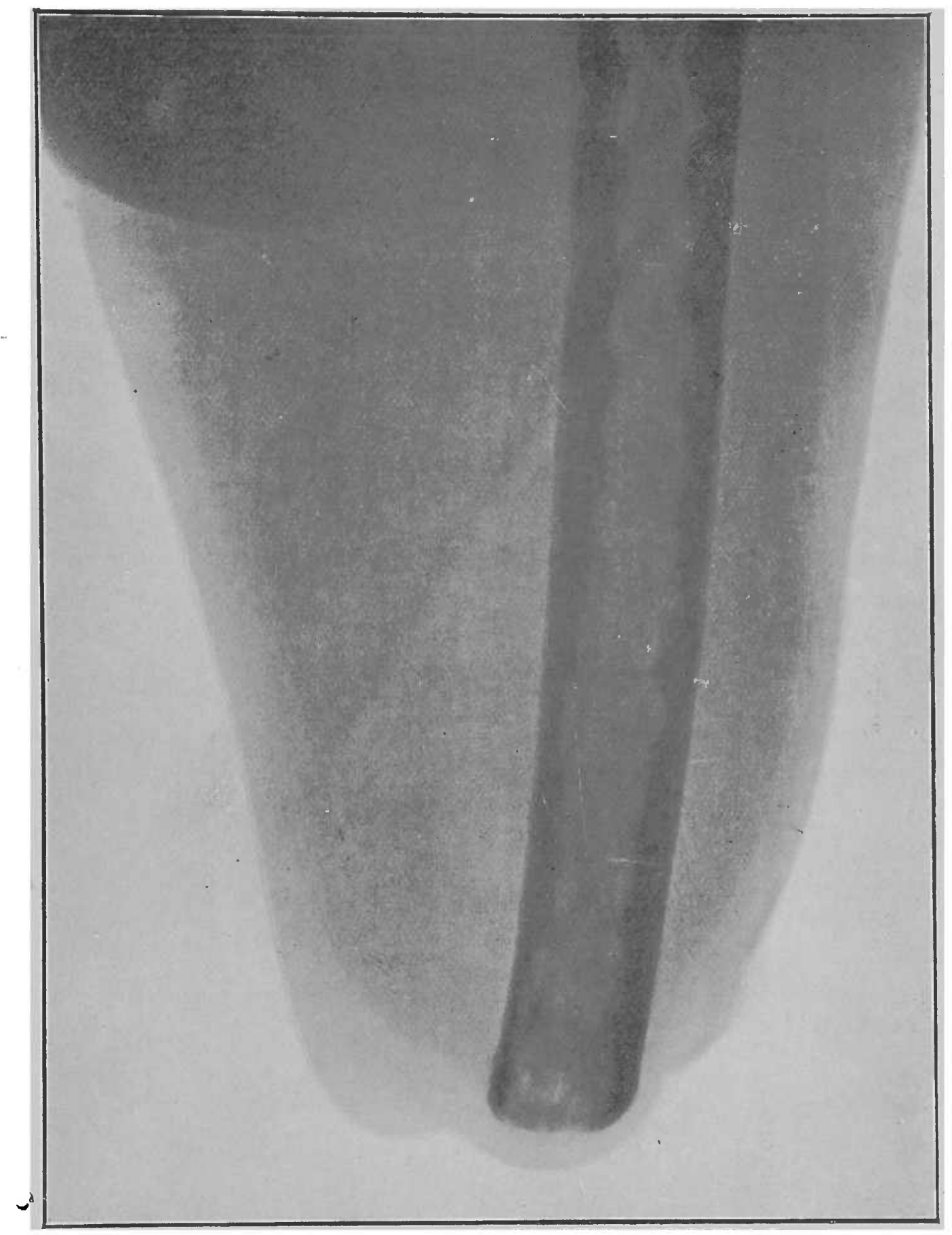

FIg. II

Radiographia do segmento superior do femur depois da amputação

Nota-se a extensão diffusa do myeloma mesmo no lugar da dierese. 

No Capitulo II o A. descreve minuciosamente a observação clinica do caso que estudou relatando os resultados dos exames de laboratorio, especialmente os exames de sangue e urina. Consta do relatorio que o doente recolheu-se ao Hospital Central da Santa Casa de Misericordia desta cidade em Agosto de 1916 apresentando uma rarefacção ossea, revelada pela radiographia, no terço superior da perna direita, attingindo a tibia e o peroneo em uma extensão de cerca de 8 centimetros.

Quando o doente retirava-se do Hospital por se ter recusado ao acto operatorio, houve fractura dos dois ossos exactamente na região citada. No dia seguinte realizou-se a intervenção cirurgica. e o segmento amputado foi enviado ao Instituto de Anatomia Pathologica da Faculdade de Medicina onde foi estabelecido o diagnostico de myeloma. Depois de ter feito varias passagens pela 3.a Enfermaria de Clinica Medica veio o doente a fallecer em 26 de Abril de 1917, sendo o cadaver enviado ao mesmo Instituto de Anatomia Pathologica onde foi realizada a necroṡcopia.

Transcrevemos os resultados do exame anatomo pathologico do membro amputado.

\section{EXAMES ANATOMO-PATHOLOGICOS.}

“O segmento amputado foi submettido a exame macro e microscopico, no Instituto de Anatomia Pathologica da Faculdade de Medicina e Cirurgia, pelos professores W. Haberfeld e Ayrosa Galvão, por nós auxiliados.

Exame macroscopico. (VIDE FIGURA v)

Dissecadas as partes molles, verificou-se que havia fractura completa, irregular, dos dois ossos da perna, sem penetração de fragmentos. Os ossos foram serrados em sentido frontal. (VIDE FIGURA v.)

Fcmur. - $O$ fragmento do femur media 12 centimetros de comprimento. A substancia compacta da face anterior do osso, muito rarefeita, permittiu a formação de uma pequena saliencia em arco. Logo abaixo do ponto em que foi praticado o corte do osso, notava-se uma formação ovoide ( 5 cents. $\times 25 \mathrm{~mm}$.) de côr vermelha intensa, tenđendo para roseo cinzento, na peripheria. $\mathrm{Na}$ epiphyse, outra pequena formação de aspecto semelhante $(1 \mathrm{~cm} . \times 7 \mathrm{~mm}$.)

Tibia e peroneo. - Juxtapostos os dois fragmentos da tibia fracturada, observava-se que a fractura se déra atravéz de uma substancia tumoriforme de côr vermelha intensa, de fórma oval ( 8 centms. $\times 4,5$ cents.) pouco consistente, que substituiu a medulla normal e o tecido osseo esponjoso, (inteiramente desapparecido) invadindo lateralmente a substancia compacta, já muito adelgaçada.

$\mathrm{Na}$ epiphyse da tibia, outras duas massas tumoriformes de aspecto semelhante $(7 \mathrm{~mm} . . \times 5 \mathrm{~mm}).(4 \mathrm{~mm} . \times 2 \mathrm{~mm}$.

No peroneo, havia substituição analoga no ponto da fractura e, desde esse ponto até a epiphyse: a medulla ossea tinha a côr vermelha. 
lioram examinados os esfregaços da medulla ossea pathologica, tomados em diversas partes, caracterizadas pelo colorido variado. $\mathrm{Na}$ parte branca da neoformação, notavam-se muitos globulos vermelhos, alguns normoblastos e, entre as cellulas brancas, muitos leucocytos eosinophilos, myelocytos eosinophilos e myeloblastos com nucleo mais ou menos corado.

$\mathrm{Na}$ parte vermelha, os myeloblastos adquiriam posição preponderante, havendo, além destes myeloides agranulados, hematias e algumas outras cellulas.

A parte vermelha escura da massa tumoriforme éra composta sómente de elementos vermelhos e sobretudo de myeloblastos.

A fina estructura das cellulas, que compõem o tecido neoformàdo, será estudada no capitulo III."

Do pormenorisado relatorio da necroscopia transcrevemos apenas os trechos mais interessantes.

"Cranco. Diametro antero posterior maximo, maior que o transverso maximo. Fórma dolichocephalica.

Abobada do craneo. - Expessura: $4 \mathrm{~mm}$. a $5 \mathrm{~mm}$.

a) face externa. - No osso parietal, proximo á sutura ságittal, uma saliencia de fórma arredondada, com 3 centimetros de diametro, de côr vermelha escura, consistencia molle, havendo uma falta de substancia ossea, comprehendendo a taboa externa e a diploe, já se tendo iniciado a destruição da taboa interna.

b) face interna. - Ha uma perda de substancia na loja da ramificação da arteria meningéa média, de fórma mais ou menos circular, com o diametro de 5 centimetros mais ou menos.

As bordas da excavação são obliquas. Houve destruição da taboa interna, diploe, sendo attingida, incipientemente, a taboa externa.

A falta de substancia corresponde exactamente a um tumor de côr vermelha-escura, que ficou adherente á dura mater. No osso parietal esquerdo, ha um fóco myelomatoso que foi interessado no córte classico da abobada craneana. (VIDE FIGURA VII.)

Dura mater. Tenra, liza, humida, conservando adherente o tumor acima mencionado. (VIDE FIGURA VIII.)

Cerebro. Peso: $1.350 \mathrm{gs}$.

Leptomeninges espessadas, arterias tenras, veias pouco injectadas, consistencia pouco augmentada.

Superficie do córte humida, não sendo notados pontos de sangue; ventriculos vasios, téla choroidéa de côr rosa pallida.

Os córtes classicos nada apresentaram de anormal.

Pulmão esquerdo. Volume normal 20 cents. $\times 15$ cents. $\times 7 \cdot$ cents. Consistencia augmentada, côr de rosa clara na parte superior, muito azulada na inferior.

Córte. Superficie lisa, côr vermelha acinzentada; sahẹ, pela expressão, muito liquido arejado.

Pulmão direito. Volume augmentado 23 cents. $\times 17$ cents. $\times 17$ cents. Adherencias á caixa thoraxica, na parte superior. Os lobos superior, médio e inferior adherentes por meio de uma membrana lacerada. 


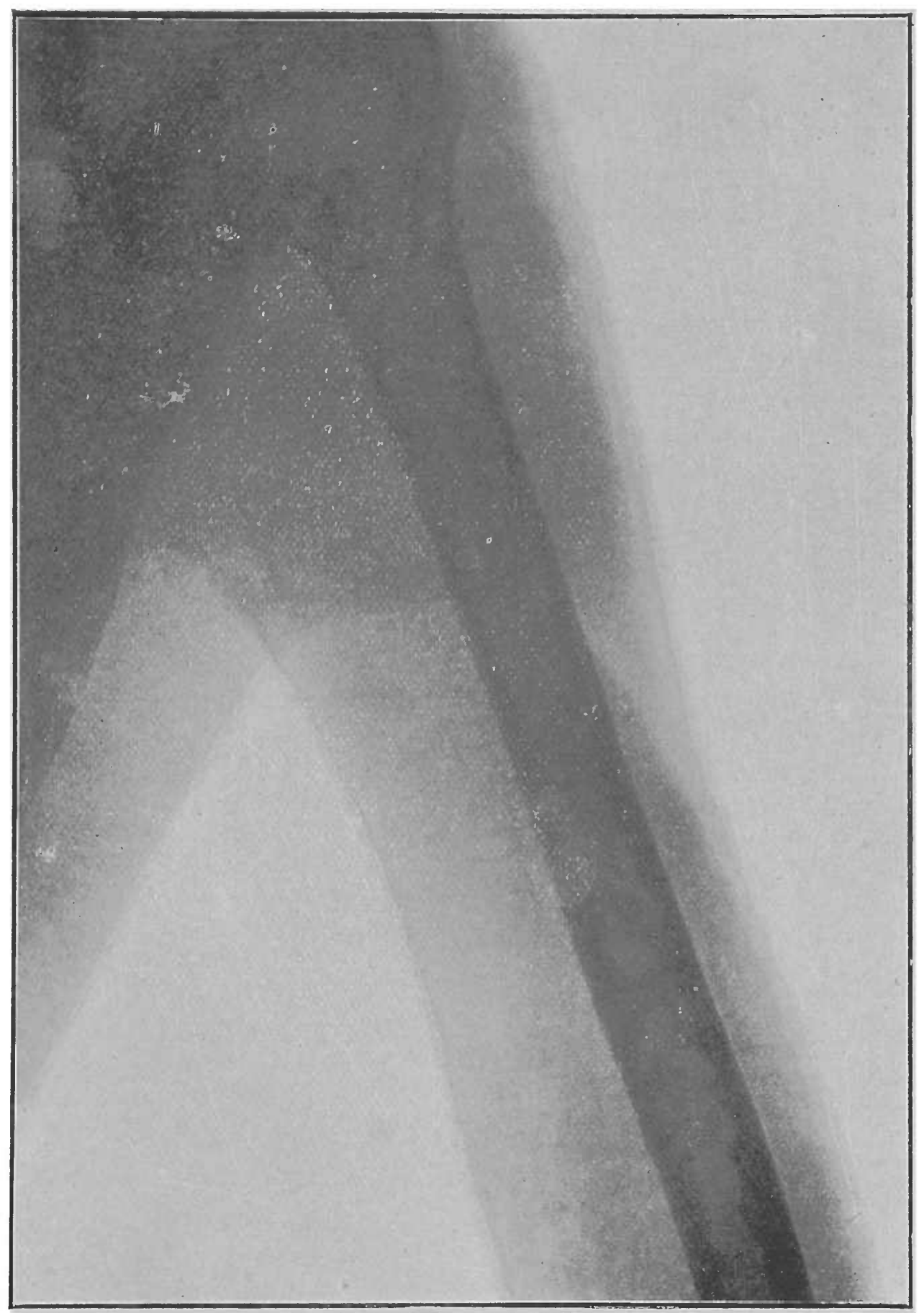

FIG. III

\section{Radiographia do humerus esquerdo}

Nota-se como o myeloma se diffunde substituindo e rarefazendo a substancia ossea esponjosa e em parte a compacta. 

Superficie opaca no lobo superior-liza e briihante no inferior. No lobo inferior, muitas manchas pequenas de côr vermelha e no superior, de côr vermelha cinzenta. Consistencia muito augmentada.

Córte. Superficie de côr vermelha acinzentada, opaca, granulosa; pela expressão, não se obtém sangue. Os ganglios broncho-pulmonares têm muito pigmento anthracotico.

Esterno. - Na face posterior do esterno-parte média - nota-se uma saliencia com a espessura de 2 centimetros, tendo 9 centimetros de extensão, no sentido do maior diametro do osso e 5 centimetros no sentido transversal, pouco consistente e de aspecto irregular.

Retirado o periosteo, encontra-se quasi todo o tecido osseo normal e a medulla ossea, (nos limites já descriptos) substituidos por massa estranha, de côr vermelha escura, com pontos mais escuros.

Ha destruição do tecido osseo esponjoso e da lamina compacta posterior, que está delgadissima e com falta de substancia em alguns pontos.

Ha uma fractura irregular na parte média da elevação descripta, dirigindo-se o traço de fractura, obliquamente, da direita para a esquerda e de cima para baixo. V. em seguida, a descripção do córte histọlogico.) (VIDE FIGURA IX.)

Columna vertebral. - O corpo da primeira vertebra lombar está quasi completamente destruido e substituido pela massa tumoriforme anteriormente descripta.

Osseo coxal. - Na fóssa iliaca externa, mais precisamente na zona média, proximo á linha semicircular anterior, ha uma destruição da lamina compacta externa e do tecido osseo esponjoso e, nos logares correspondentes, apparece a massa tumoriforme já descripta.

\section{OSSOS DOS MEMBROS INFERIORES E SUPERIORES.}

a) Tibia esquerda. (VIDE FIGURA $\mathrm{x}$.)

Nos dois terços superiores do osso, todo o tecido esponjoso e a medulla ossea normal estão substituidos pela massa de côr vermelha escura, com pontos mais escuros, bastante consistente.

Observa-se que, em muitos pontos, a massa tumoriforme invadiu a substancia compacta, substituindo-a. $\mathrm{Na}$ extremidade superior do osso, a in vasão foi mais accentuada, estando, em grande parte, destruida a substancia compacta. (Vide fig. XIV.) (Córte histologico.)

Tibia direita. - Já anteriormente descripta.

Peroneo direito. - Já descripto.

Femur direito. - Amputado no terço inferior. (Vide fig. XI.)

$O$ tecido esponjoso e a medulla ossea normal, inteiramente desapparecidos e suppridos pela massa estranha descripta.

Houve tambem invasão da substancia compacta, mais accentuadamente no collo do femur. Entre a cabeça femural e o grande trochanter, o desapparecimento da substancia compacta produziu o encurtamento do collo anatomico. No ponto da amputação, ha um callo osseo, duro, quasi desapparecido. (Vide fig. XIII, córte histologico.)

Femur csquerdo. - Toda a medulla ossea está nas condições anteriormente descriptas. 
Ao nivel do collo cirurgico do femur e para o seu lado externo, ha uma parte tumoral mais escura, com as dimensões de 4 cents. $\times 2$ cents., que, invadindo a substancia ossea compacta, deixa-a reduzida a uma tenue lamina flexivel.

$\mathrm{Na}$ extremidade inferior, ao nivel do triangulo popliteo, ha uma porção mais escura, com as dimensões de 5 cents. $\times 3$ cents., que produziu a demolição quasi completa do tecido osseo compacto.

Humerus direito. - Mesmo aspecto, havendo ligeiras destruições de tecido osseo compacto.

A parte esponjosa da cabeça e da extremidade inferior parece poupada.

Hincrus esquerdo. (Vide fig. X.)

$O$ processo é mais accentuado.

$\mathrm{Na}$ união do terço superior com os dois terços inferiores, nota-se uma região mais escura, com as dimensões de 2 centimetros $\times 1,5$ centimetros.

Radius esquerdo. - O mesmo processo. A parte anterior da substancia compacta da cupula radial está quasi destruida.

$\mathrm{Si}$ bem que, em menor escala, toda a parte anterior do terço superior da diaphyse radial apresenta o mesmo aspecto.

Radius direito. - Mesmo processo, mais accentua'do no terço superior.

Invasão accentuada da parte compacta da cúpula radial.

Cubitas ésquerdo. - Mesmo processo. Um fócn mais escuro de 3 centimetros de diametro, na união do terço superior com os dois terços inferiores."

Segue-se um circumstanciado estudo histo-pathologico do qual destacaremos os pontos mais importantes.

"II. - MEDULla ESPINAL.

a) Medulla dorsal superior. - Hematoxylina-eosina.

LEPTOMENINGES.

Tanto nas leptomeninges, como nas raizes nervosas, as lesões são muito accentuadas.

Observámos uma infiltração consideravel das membranas envolventes e das raizes nervosas. As cellulas dessa infiltração, na sua grande maioria, são leucocytos neutrophilos.

A intensidade da infiltração é a mesma em toda a circumferencia da medulla.

Nota-se um edema muito accentuado das leptomeninges. Os vasos sanguineos estão muito injectados e os globulos brancos, muito abundantes, acham-se collocados em posição marginal e alguns permigram as paredes vasaes.

Substancia branca e substancia cinzenta.

Toda a medulla - tanto a substancia branca, como a substancia cinzenta, - apresenta uma proliferação cellular, bem visivel, sobretudo nos cordões anteriores e lateraes.

O canal central, muito nitido, tem uma luz muito larga. As cellulas epen. dymaes estão bem conservadas.

Todos os vasos sanguineos, sobretudo da substancia cinzenta, mostram-se muito injectados e na substancia branca têm uma infiltração cellular perivascular.

As cellulas dos cornos anteriores não apresentam lesões bem reconheciveis. 


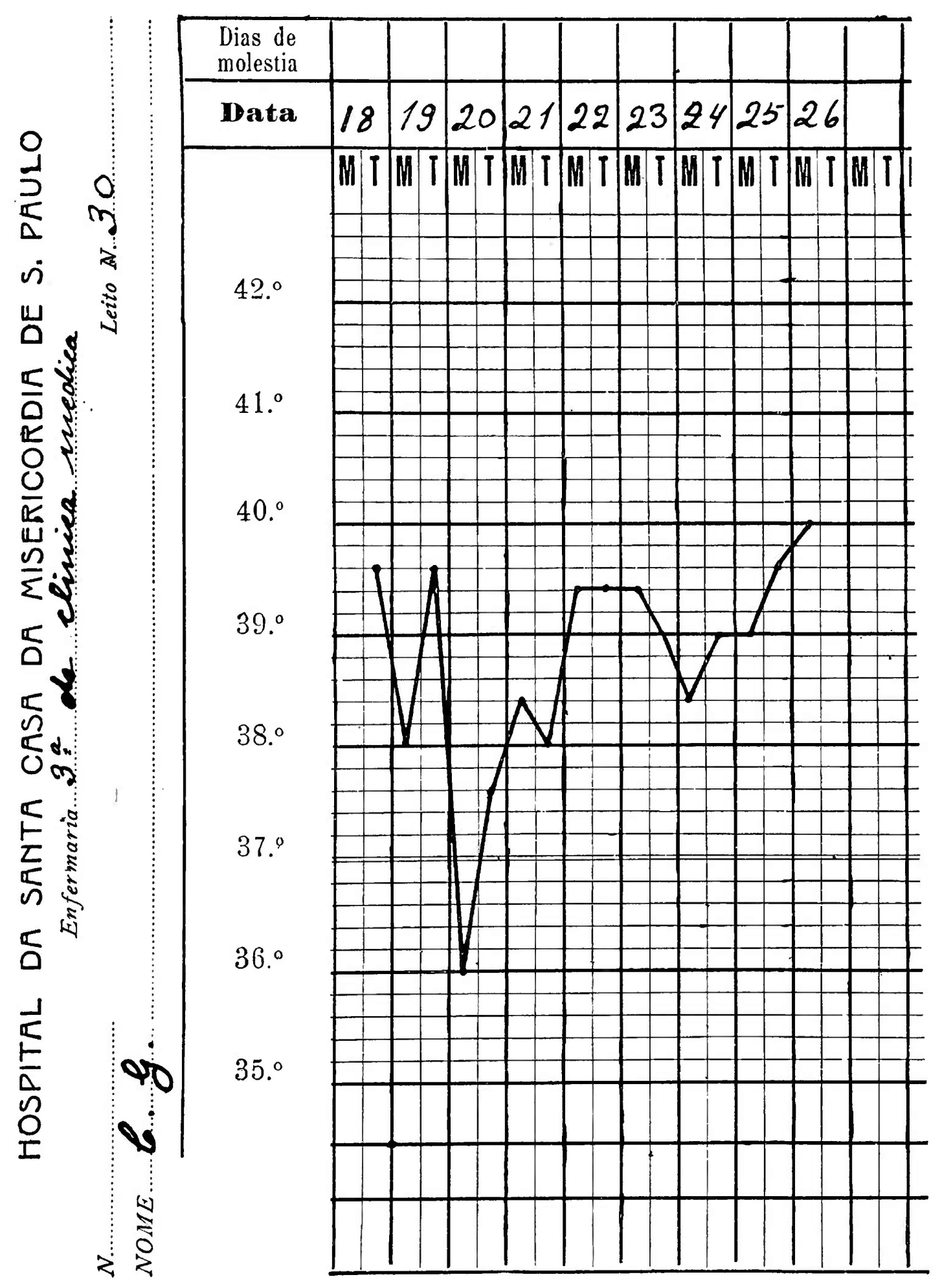



As cellulas da columna de Clarke estão bem conservadas, havendo apenas algumas, com o corpo tigroide um pouco apagado.

A substancia gelatinosa de Rolando está muito rica em cellulas.

Notamos ainda, na substancia branca, degeneração hyidropica de muitas fibras nervosas e algumas vezes, o cylindro-eixo, dentro de uma cavidade, do tamanho de uma ce!lula adiposa.

- Em outro córte histologico, corado pelo methodo de V. Gieson, nada mais foi encontrado, além do que já foi descripto.

b) Medulla cervical. - Hematoxylina-eosina.

Mesmo processo inflammatorio, muito accentuado.

c) Medulla sacral superior. - Hematoxylina-eosina.

As mesmas lesões, mais accentuadas na parte posterior.

NOTA. - Em toda medulla, os fibroblastos apresentam grande quantidade de pigmento melanico.

IV. - PUlMão. - Hematoxylina e eosina.

Os alveolos, muito dilatados, são tomados por massas fibrinosas, grande numero de globulos vermelhos e poucos leucocytos polymorpho-nucleares neutrophilos. Observam-se algumas cellulas alvealares, descamadas.

Os septos alveolares, bem estreitos, com capillares que quasi não contém sangue.

Em varios pontos, ha depositos de pigmento anthracotico.

- Em outro córte; do pulmão, as cellulas brancas já são mais accentuadas. Notam-se escassos depositos calcareos, nos septos alveolares.

V. - BAço. - Hemataxylina-eosina.

A estructura é pouco visivel, por causa da grande quantidade de sangue, havendo hemorrhagias diffusas no parenchyma esplenico.

Os corpusculos de Malpighi estão atrophiados. A polpa vermelha está muito rica em globulos vermelhos e cellulas da polpa e os seios esplenicos, pouco ou nada visiveis. lular.

$\mathrm{Ha}$ grande quantidade de pigmento hemosiderotico, intra e extra-cel-

VI. - FIGADo. - Hematoxylina-eosina.

A estructura está em grande parte desapparecida, sendo muito consideravel o augmento de sangue, nos capillares hepaticos.

As trabeculas hepaticas estão muito atrophiadas, por compressão. No tecido periacinoso, ha uma pequena infiltração parvicellular.

Córte histologico, corado pelo acido osmico.

As gotticulas de graxa destacam-se nitidamente, (coradas em negro) nas cellulas hepaticas da peripheria dos acinos.

VIII. - Estomago. - Hematoxylina-eosina.

Entre as glandulas do fundo do estomago, notam-se incrustações calcares, relativamente abundantes.

XI. - RIM. - Hematoxylina-eosina.

Os glomerulos estão em começo de fibrose e os vasos sanguineos, injectados. O tecido intersticial está um pouco proliferado. Quasi todos os tubulos renaes estão cheios de cylindros hyalinos, intensamente corados pela eosina.

Em diversos tubulos notam-se pequenos blócos agglomerados de substancia calcarea, que, ás vezes, obstroem-n'os completamente. (Vide figura XII.) 
XII. - RIM. - Acido osmico.

Glomerulos e tubulos renaes estão polvilhados de pequeninos pontos riegros, resultantes da reacção do acido osmico sobre as gotticulas de graxa.

XIII. - MEdULIA OSSEA do RADIo. - Hematoxylina-eosina.

Córte histologico da medulla ossea do radio, praticado em um fóco distinguivel macroscopicamente pela coloração vermelha-escura intensa.

O exame permittiu a averiguação dos seguintes elementos:

- a) cellulas adiposas conservadas e em destruição, representando os restos da medulla antiga.

- b) agglomerações de saes calcareos, formando blócos grosseiros.

- c) vasos venosos, arterias e arteriolas, cercadas por tecido conjunctivo frouxo, bem desenvolvido.

O sangue intravascular não apresenta anormalidade em sua composição, não havendo invasão das cellulas tumoraes, no tecido circulante.

d) elementos sanguineos, entre as cellulas tumoraes, attestando uma hemorrhagia diffusa.

- c) myeloblastos muito numerosos, com um, dois e tres nucleos, attingindo algumas dessas cellulas agranulosas, 10 micra de diametro.

Essas cellulas geralmente, muito intimamente agrupadas, têm o tamanho médio de 2 a 3 vezes o diametro d'um globulo vermelho.

O protoplasma, uniformemente corado pela eosina, não apresenta granulações.

Alguns myeloblastos têm 2 a 3 nucleolos e são frequentes as mitoses. Não existe substancia fibrillar intercellular.

XIV. - MYeloma DA ABOBAdA CRANEANA. - Hematoxylina-eosina.

Córte histologico do myeloma da calota craneana, que na necroscopia se destacou, ficando adherente á dura-mater.

- A fina estructura é a mesma já descripta no corte anterior, notandó-se, apenas, maior quantidade de sangue intercellular.

Numerosas cellulas myelomatosas estão em destruição por caryorrhexis. $\mathrm{O}$ arcabouço é apenas representado por vasos capillares e pré-capillares.

XV. - mYeloma dA ABobada. CRAneana. - Acido osmico.

Raras cellulas apresentam, no seu interior, pequenos pontos negros, resultantes da reacção do acido osmico sobre gotticulas finas e multiplas de graxa neutra.

A grande maioria daș cellulas não apresenta essa reacção.

- Nos demais ossos, a medulla tem a mesma estructura histologica.

XVI. - Esterno. - Hematoxylina-eosina.

O tecido osseo está quasi desapparecido, notando-se apenas, raras trabeculas muito finas, com poucas cellulas e sem estructura lamellar visivel. Ao redor das trabeculas, e entre ellas, assentam as cellulas myelomatosas e pouco tecido fibroso. Granulações de pigmento anthracotico entremeiạm as cellulas do myeloma, mais ou menos uniformemente espalhadas.

$\mathrm{Na}$ peripheria do preparado histologico, ha cartilagem hyalina, com processo de ossificação endochondral.

Este processo, muito pouco accentuado, consiste mais em uma calcificação. da cartilagem, do que na producção de verdadeiro tecido osseo. A parte medullar dessa ossificação é formada - na cartilagem proxima - por tecido fibroso pobre em vasos e em cellulas e, na cartilagem distante, está inteiramente misturada e sem limites com as cellulas do myeloma.

$\mathrm{Ha}$ formação franca de muito tecido chondro-osteoide, verificando-se nitidamente como o tecido cartilaginoso, proliferado e em parte calcificado, transforma-se directamente em tecido de estructura ossea. 


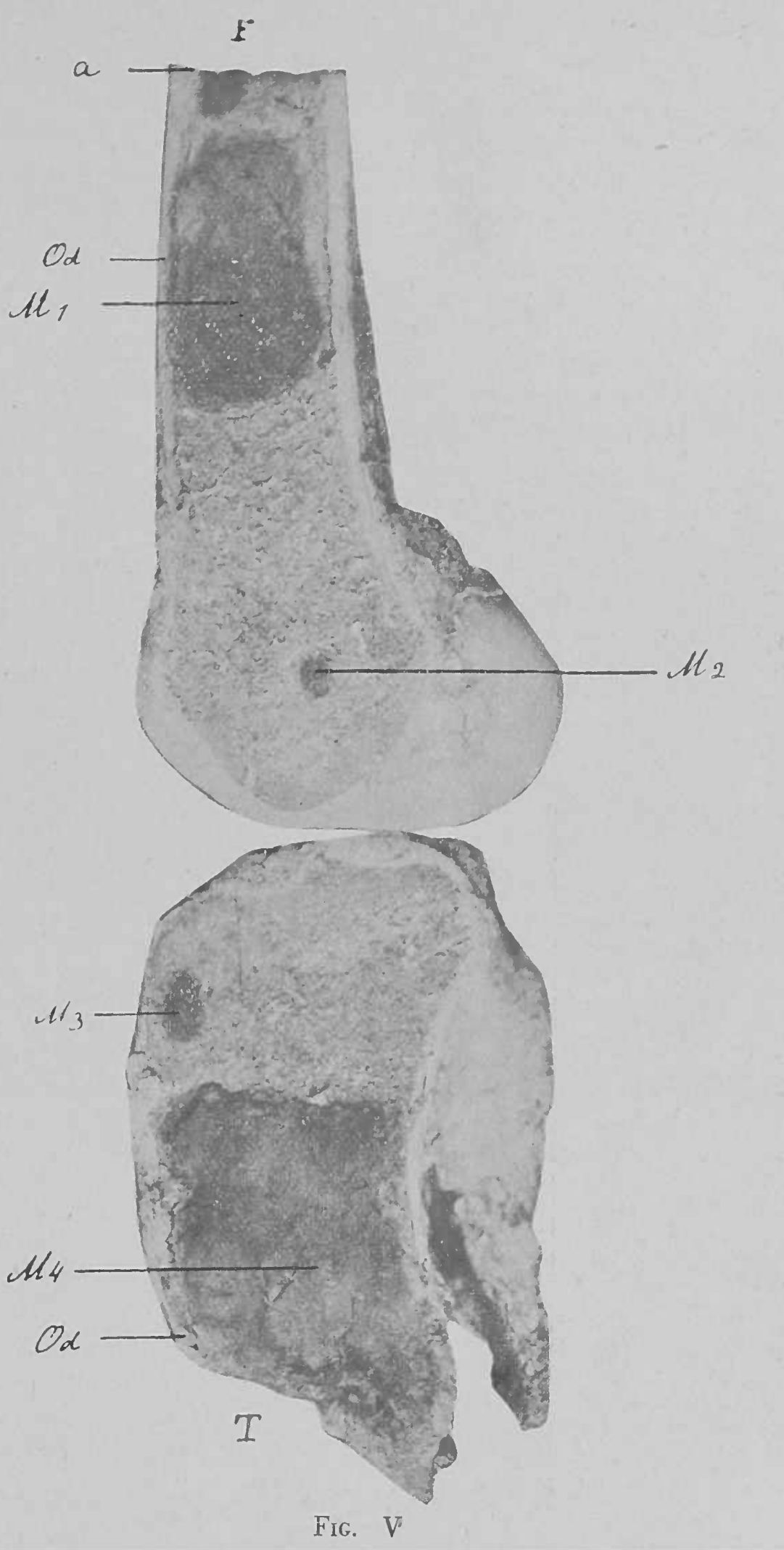

Parte amputada do membro inferior direito acima da fractura

( $M$ 4, corresponde á parte superior do espaço claro da tibia direito revelado pela radiographia - FIG. I).

O contorno irregular inferior foi produzido pela fractura.

$F$ - Extremidade inferior do femur (amputado) $a$ - dierese; $O d$ - osso destruido pelo myeloma;

M 1 - Myeloma situado logo abaixo do ponto de amputação; M 2 - Myeloma pequeno.

$T$ - Extremidade superior da tibia (fracturada) M 3 - Myeloma pequeno;

$M$ 4-Myeloma existente no lugar da fractura;

$O d$ - Osso destruido pelo myeloma. 

- Em outro córte do esterno, nota-se revestindo a parte ossea peripho - rica, uma camada muito fina de osso neoformado, assentando sobre uma fileira de osteoblastos. Essa orla tegmentaria do osso apresenta um colorido vermelho, mais intenso do que o do osso antigo.

XVII. - FEMUR. - Hematoxylina-eosina.

a) Collo do femur. Vide fig. XIII.

O tecido osseo esponjoso está completamente desapparecido e substituido 1,elo myeloma, que se apresenta ćom vasos de parede muito fina, de luz avantajada e plenos de sangue.

$\mathrm{O}$ tecido osseo compacto antigo está muito reduzido e em muitos logares, sem os canaes haversianos; estes, quando existem, estão muito achatados.

Revestindo a parte peripherica do osso antigo, observa-se nitidamente, uma neoformação ossea, que se caracteriza por trabeculas osseas dispostas perpendicularmente á superficie do osso antigo (osteophyto) e deste separada por tecido conjunctivo, rico em cellulas.

O tecido osseo neoformado repousa sobre um órla osteoblastica, muito niticla.

b) diaphyse do femur.

Ha substituição das trabeculas osseas do tecido esponjoso, assestando-se, em seu logar, o myeloma, com abundantes hemorrhagias diffusas e restos de cellulas adiposas. O tecido compacto, cuja superficie interna é irregular, não demonstra lesões histologicas. $O$ processo myelomatoso ainda não chegou em contacto directo com a substancia ossea compacta, da qual está separado por uma faixa de tecido conjunctivo, prenhe de cellulas.

XVIII. - TIBIA. - Hematoxylina-eosina.

Estructura semelhante á do femur.

A substancia ossea muito reduzida, quasi sem canaes de Havers, dando mais o aspecto de osso reticular, do que de osso lamellar.

O osso continía directamente com o myeloma, havendo na superficie de contacto uma bordadura osteoide, muito fina, de osso descalcificado. (Vide fig. XIV.)

XIX. - TIBIA. - (amputada.)

Histologicamente, o myeloma têm os caracteres já descriptos em outros ossos: cellulas intimamente agrupadas, tomando por isso, a fórma polyedrica, com protoplasma quasi uniformemente corado pela eosina e sem granulações. Não existe substancia fibrillar intercellular. Não ha invasão das cellulas sanguineas no sangue intravascular, cuja composição é normal. Ha hemorrhagias diffusas, entre as cellulas myelomatosas. Os vasos sanguineos são cercados por um tecido conjunctivo frouxo, bem desenvolvido.

XX. - PERoneo (amputado).

O quadro histologico é o mesmo: cellulas myelomatosas, pequenos vasos e globulos vermelhos.

A substancia esponjosa estando completamente destruida destaca-se entre o myeloma e a substancia ossea compacta, um fino fasciculo de tecido conjunctivo, falho em alguns pontos. Quasi não ha canaes de Havers e alguns estão cheios de cellulas myeloblasticas.

$\mathrm{Na}$ parte externa da substancia compacta, ha uma órla osteoblastica, estando os osteoblastos em elaboração de tecido osseo. $O$ tecido osseo neoformado destaca-se bem do osso antigo, pela sua coloração mais clara. 
Hypophyse. - No lobo anterior da hypophyse, ha prevalencia das cellulas acidophilas e, em alguns pontos, no estroma intracinoso, notam-se depositos de saes calcareos, geralmente de fórma alongada.

Ganglio de Gasser. - Na peripheria do ganglio, ha infiltração leucocytaria muito accentuada das leptomeninges, com verdadeiros fócos de puz. A infiltração leucocytaria invade, em parte, o proprio ganglio nervoso.

Observam-se ainda agglomerados de areia cerebral, em fórma de corpos psammosos concentricos."

O Capitulo III é reservado para o estudo das cellulas myelomatosas e delle faremos a transcripção integral.

\section{“ESTUDO DAS CELLULAS MYELOMATOSAS.}

\section{1) Fórma E dimENSÕEs.}

As cellulas que compõem o tecido medullar neoformado são todas identicas entre si, salvo pequenas variantes do tamanho e do numero de nucleos e de nucleolos, como se vê perfeitamente pelo exame da figura VI. O diametro médio das cellulas varia entre 15 e 20 micra, at'tingindo, em a!guns elementos cellulares, o dobro dessa dimensão.

Quando isoladas, ellas têm a fórma oval e, quando reunidas, tornam-se polyedricas, pela compressão que umas exercem sobre as outras.

O nucleo, que occupa mais ou menos a metade do corpo protoplasmatico, tem a fórma redonda e é geralmente collocado em posição excentrica.

O seu tamanho médio é comparavel ao de um globulo vermelho, alcansando ás vezes o dobro do diametro de uma hematia.

$\mathrm{Ha}$ ainda cellulas gigantes, com dois, tres e quatro nucleos, tendo estes até cinco micra de diametro.

\section{2) Estructura.}

A estructura nuclear varía conforme o methodo de coloração empregado. Pela coloração commum, com a hematoxylina-eosina, as cellulas tomam o aspecto total das plasmazellen. Ellas têm fórma oval e o nucleo, redondo e excentricamente collocado, é provido de numerosos granulos chromaticos, reunidos na peripheria, e que convergem para o centro, adelgaçando-se á maneira dos raios de uma roda.

Um exame mais particularisado demonstra, porém, que a grande maioria dos nucleos tem a estructura chromatica bem mais fina e delicada que a das cellulas plasmaticas. Em redor do nucleo, distingue-se apenas uma delgada membrana e geralmente, elle tem um unico nucleolo; ás vezes, porém, sobretudo nas cellulas maiores, apresenta dois e, mais raramente, tres nucleos. Estes, pela coloração de Pappenhein (verde methyla-pyronina,) tomam a coloração vermelha intensa como se observa na figura que apresentamos.

Nos córtes histologicos, corados pelo processo commum, (hematoxylina-eosina), o protoplasma cellular toma uma côr rosea bastante fórțe, que não permitte a-apreciação das minucias, emquanto que, no esfregaço, corado pelos methodos especificos, elle se apresenta ligeiramente granuloso vacuolar, desenho este que se torna ás vezes bem evidente, na coloração de Pappenheim. 


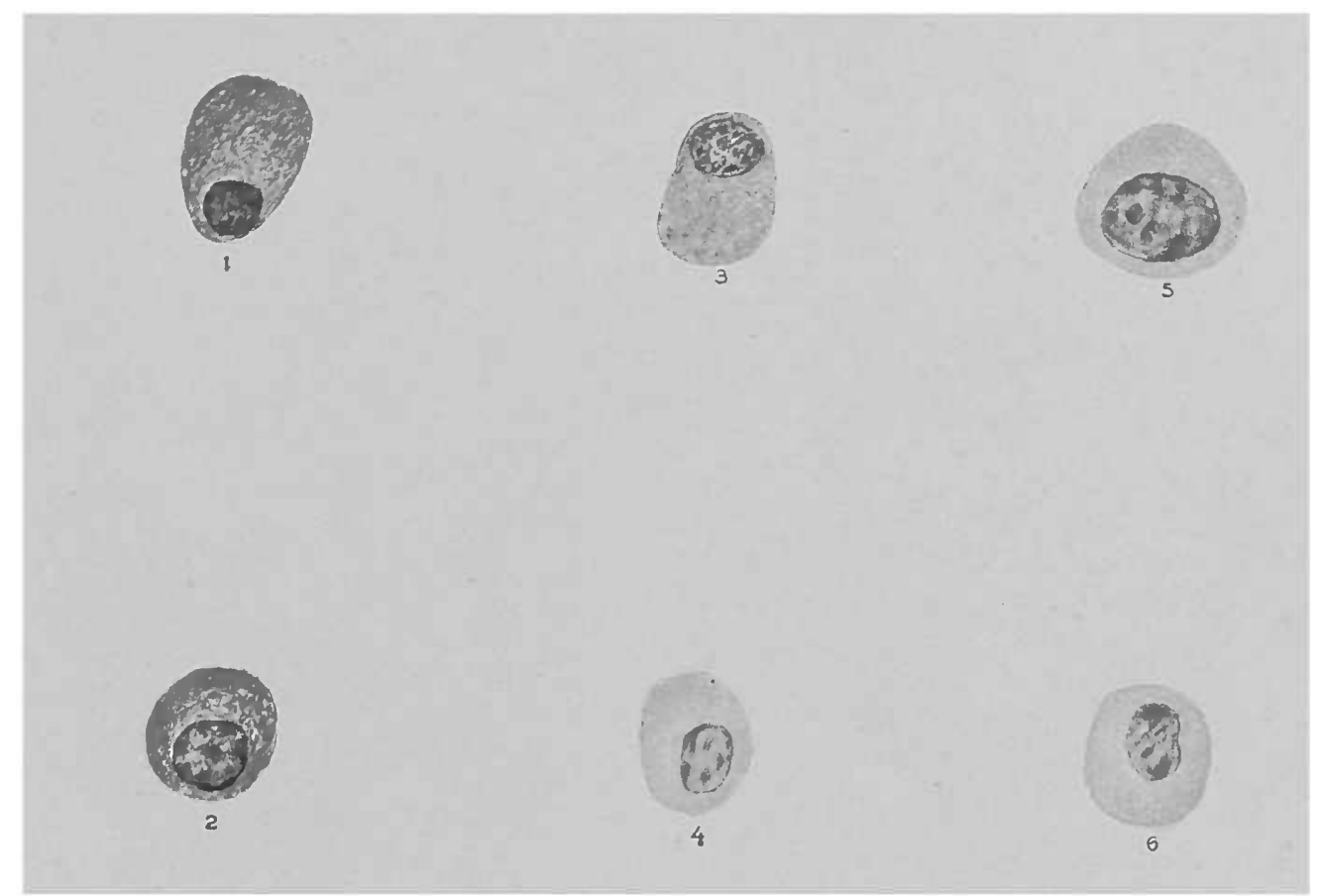

Coloração especifica de Pappenheim para plasmazellen

(VERDE METHYI.A PYRONINA)

Augmento: immersão.

1 e 2 - Plasmazellen de um fóco inflammatorio de medulla ossea, com protoplasma corado intensamente em vermelho e grosseiramente granuloso, mostrando bem a aureola clara em torno do nucleo que tem o arcabouço chromatico caracteristico, sobretudo em 2.

3 - Cellula do esfregaço do myeloma, mostrando um protoplasma de côr muito differente, diffusamente lilaz, com tons roseos.

4 - Cellula do myeloma, em corte histologico, apresentando um aspecto muito differente das cellulas 1 e 2, apezar de tratadas ao mesmo tempo, pelo mesmo processo.

5 e 6 - Cellulas do parenchyma medullar, da mesma medulla em que foram encontradas as plasmacellulas figuradas em 1 e 2 . Nota-se a grande semelhança destas cellulas, com a cellula 4 . 



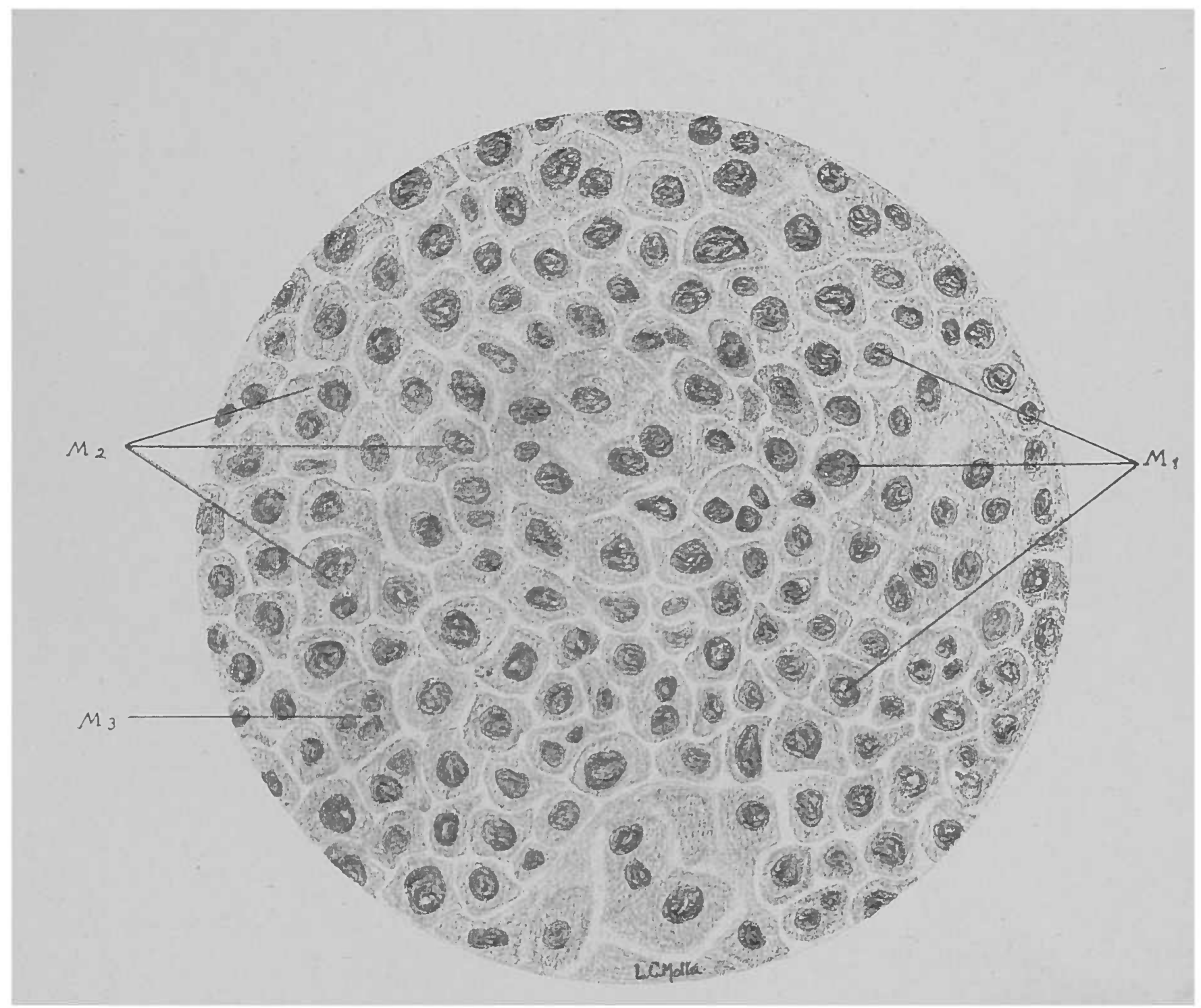

FIC. VI

\section{Esfregaço do myeloma corado pelo corante de Leishmann;}

Observa-se um polymorphismo cellular muito accentuado. Augmento: immersão.

MI $l$ - Myeloblastos com nucleo unico.

M 2 - Myeloblastos com dois nucleos.

.I 3 - Myeloblastos com tres nucleos. 

O verde de methyla-pyronina, dá ao protoplasma das cellulas nos córtes histologicos, um tom azul lilaz as vezes rosa lilaz que é identico ao das cellulas dos esfregaços, jámais chegando a produzir o colorido vermelho escuro lucido tão caracteristico das plasmazellen (Vide fig. respectiva.)

Por acaso, tivemos á nossa disposição uma medulla ossea hyperplastica, com fóco de inflammação chronica, fixada do mesmo modo que a nossa medulla myelomatosa e que nos forneceu abundante material, para exame comparativo.

Em preparados obtidos por identico processo e corados simultaneamente pela coloração especifica de Pappenhein, que permitte distinguir os elementos da série lymphocytaria dos elementos da série myelocytaria, conseguimos salientar perfeitamente' a differença entre as nossas cellulas e as cellulas plasmaticas.

No fóco de inflammação da medulla ossea hyperplastica, a coloração especifica destacou nitidamente as cellulas de plasma, (Vide a figura) com todos os caracteres das plasmazellen de Unna-Marchalko, apresentando até a aureola perinuclear bem pronunciada.

Estas cellulas parenchymatosas da medulla hyperplastica, não coradas especificamente e, por isso bem destacaveis das plasmazellen de Unna-Marchalko, têm quasi perfeita semelhança com as do nosso caso, tanto em relação ao nucleo, com ao protoplasma e ao colorido lilaz azulado deste ultimo.

Para a reacção da oxydase, empreg'́mos tambem o processo comparativo, fazendo actuar o reagente de Schutze (naphtol alpha e dymethylparaphenylendiamina), sobre esfregaços de sangue normal, de leucemia myeloide, de leucemia lymphatica, de myeloma e sobre córtes histologicos da neoformação medullar.

As cellulas da linha myeloide (leucemia myelogenica, e polymorpho-nucleares do sangue normal) tomaram a côr caracteristica e as cellulas da série lymphatica (leucemia lymphatica e lymphocytos do sangue normal) ficaram incolores, provando deste modo o valor do reactivo.

Nos córtes histologicos do myeloblastoma, sómente algumas cellulas de determinadas regiões dos preparados tomaram a coloracão azul preto.

Examinando outros preparados de córtes em série pelo corante commum (hematoxylina-cosina) foi facil verificar que as cellulas que tinham soffrido a acção do indophenol synthetico eram leucocytos presentes nas hemorrhagias do myeloma.

Podemos, portanto, affirmar, categoricamente, que as cellulas do myeloma não deram a reacção da oxydase.

\section{3) Figuras de divisão.}

Conseguimos observar figuras de divisão por caryocinese indirecta com relativa frequencia, apresentando-se no campo microscopico de augmento grande, até cinco figuras de mitose.

NOTA. - Salientamos que estes nossos estudos foram feitos em parte com material vivo (logo após a amputação da perna) e em menor parte, com material colhido na necroscopia.

\section{4) Natureza das cellulas. E classificaÇÃo.}

Vejamos agora, methodicamente, qual é a natureza das cellulas e em que grupo poderemos classificar o nosso caso.

1) Erythroblastoma.

As cellulas que, em essencia, constituem a neoformação medullar, não têm semelhança alguma com erythroblastos, nem possuem hemoglobina, 
fodendo portanto, ser logo excluido esse grupo constituido por Ribbert e do qual ha mais uma observação de Copelli em 1912, citada e resumida por Martelli.

Aliás, Ribbert, apesar da sua grande autoridade, tem sido fustigado pela critica de alguns autores, que não acceitam a identidade das cellulas do seu caso de myeloma, com os globulos vermelhos nucleados.

\section{2) Lymphocytoma (Bignami, Grawitz, Wieland.)}

Hirschfeld, (Kraus. e Brughs 1915) nos seus commentarios sobre os myelomas lymphaticos ou lymphocytomas, diz que, muito provavelmente os myeloblastos foram confundidos com lymphocytos, pois "a verdadeira existencia de lymphocytos, na medulla ossea, é ainda muito combatida. embóra muitas vezes affirmada".

$\mathrm{Diz}$ mais o autor: "Os methodos modernos de coloração e as reacções microchimicas, para distinguir lymphocytos e myeloblastos, foram applicados em poucos casos e nunca em myelomas, (o autor, naturalmente, desconhecia os casos em que o processo foi applicado), e, por isso, devemos considerar indecisa a questão, si existem myelomas multiplos de verdadeiros lymphocytos."

Em nosso caso, a classificação das cellulas entre os lymphocytos poude ser completamente afastada, não só pelo seu aspecto geral, muito differente, como tambem porque o largo anel de protoplasma não tomou o colorido vermelho especifico, com o emprego do verde de methyla-pyronina de Pappenheim.

3) Myelocytoma. (Beitzk, Albert Herz.)

A simples coloração pelo corante de Leishmann permittiu a exclusão dos granulocytos.

- Pondo de parte os casos mixtos, como por exemplo o de Versé (3.0 caso), em que entravam na composição da neoplasia, segundo a descripção do autor, cellulas muito variadas (myelocytos, myeloblastos, erythroblastos, lymphocytos, etc.) e.os casos de erythromyeloblastoma, os primeiros não parecendo myeloma verdadeiro, e os segundos, melhor considerados como myelomas com diffusas hemorrhagias, só nos resta, por exclusão, estabelecer o diagnostico differencial entre os plasmocytomas e os myeloblas- . tomas.

\section{4) Plasmocytomas e myeloblastomas.}

Até ha pouco tempo, os autores consideravam a maioria dos casos de myeloma como formados de cellulas myeloblasticas; porém, ultimamente, sobretudo por parte dos autores americanos, em grande numero de casos têm sido descriptas as plasmazellen como responsaveis pela proliferação medullar.

Podemos desde já dizer que, a priori, parece pouco provavel a frequencia tão pronunciada dos plasmocytomas, igualando ou sobrepujando os casos de myelomas, compostos de cellulas, que normalmente tomam parte na composição histologica da medulla ossea, como os myelocytos e myeloblastos.

Realmene, é muito mais natural que a proliferação medullar se faça á custa destas cellulas, do que das plasmazellen que existem na medulla, em caracter muito accessorio.

Por outro lado, como as cellulas plamaticas existem em toda parte do organismo, entrando na constituição do tecido conjunctivo e de preferencia no estomago, intestino, nariz, etc., é difficil, comprehender por que fica a proliferação plasmocellular, nos casos de myeloma, quasi exclusivamente restricta ao esqueleto e não sejam mais frequentes os plasmocytomas extramedullares. 


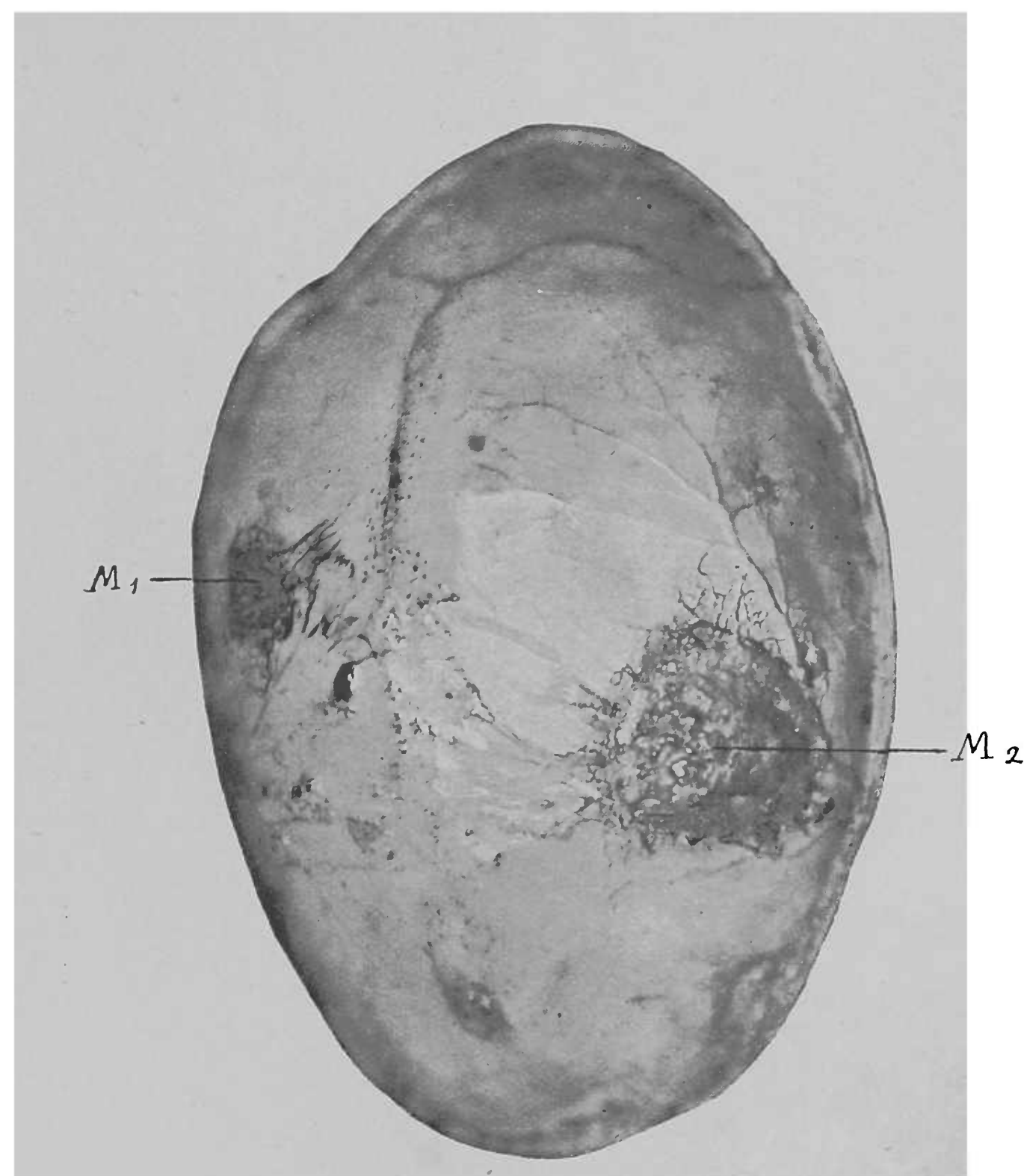

FIG. VII

\section{Abobada do craneo}

(superficie interna)

M 1 - Fóco Myelomatoso.

M 2 - Perda de Substancia, correspondente ao myeloma que ficou adherente á dura mater. 



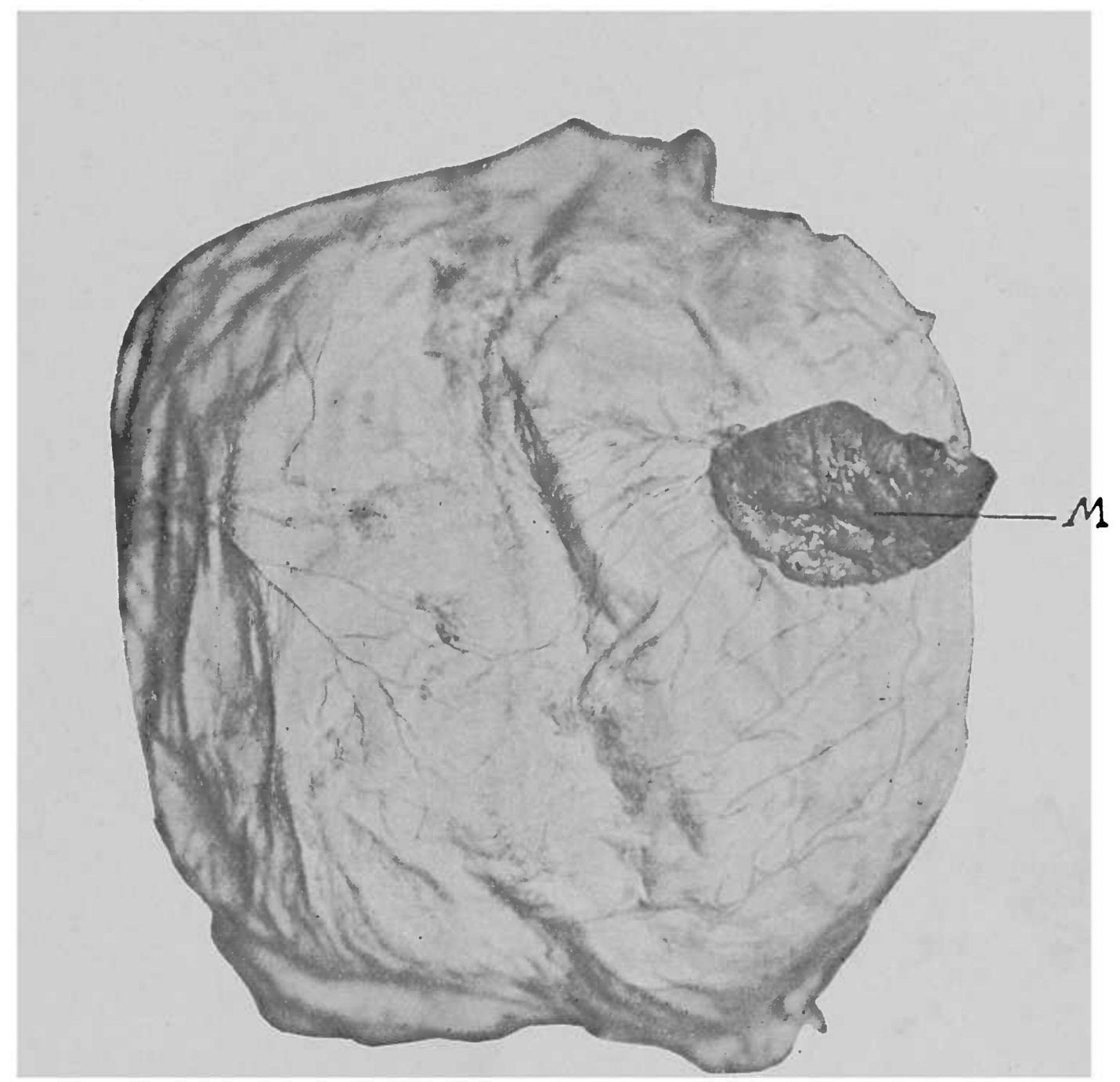

FIG. VIII

\section{Dura-mater}

$M$ - Myeloma adherente á dura mater. 



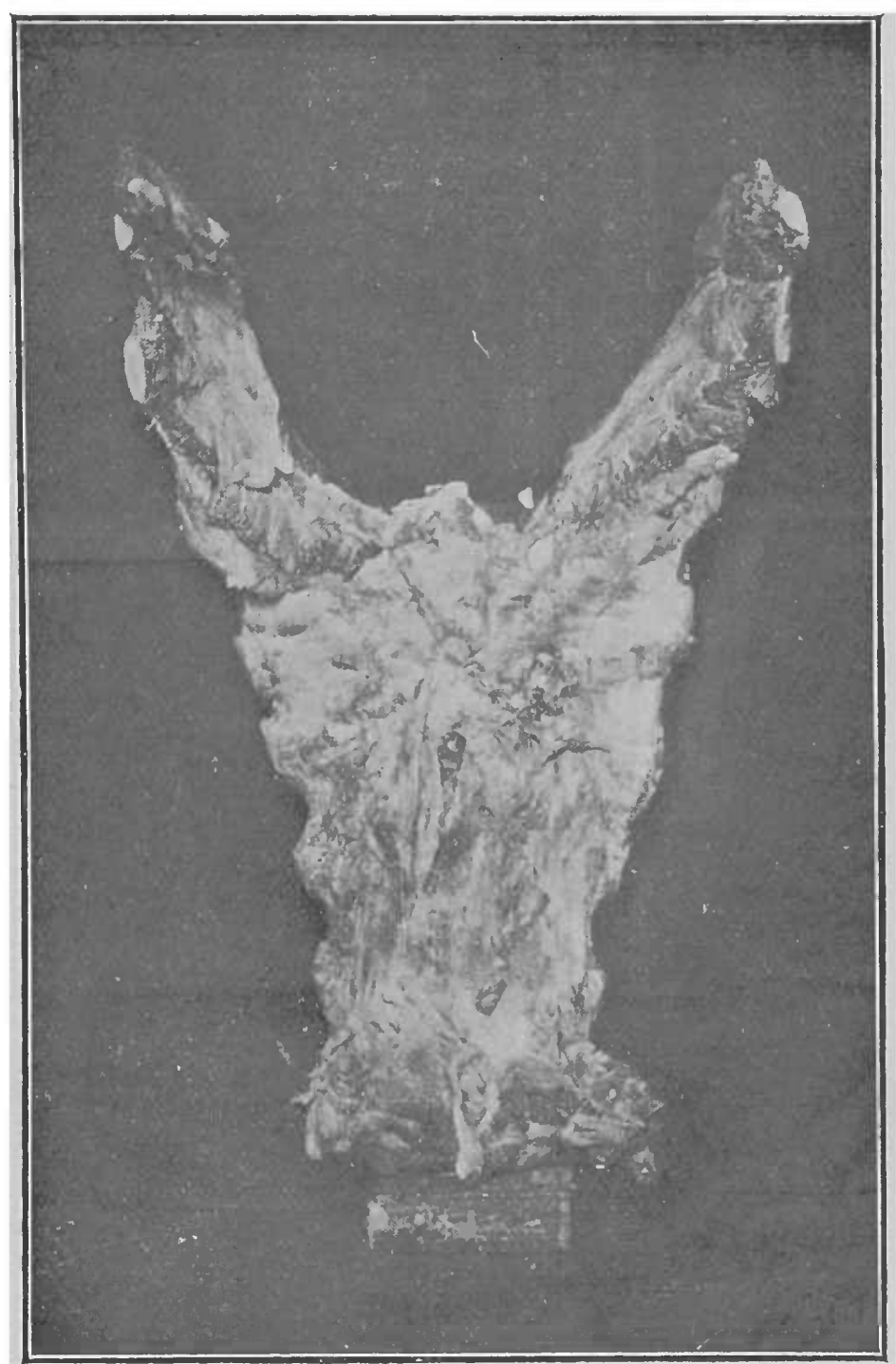

FIG. IX

\section{Piastrāo chondro esternal}

(Superficie posterior)

Abrangendo o piastrão nota-se um tumor noduloso.

Ao natural a peça é mais interessante de que vista em photographia, por não ser possivel obtel-a de perfil. 

Lembremos, ainda, que, em nosso caso, são abundantes as figuras de mitose e, si é verdade que Fusari, por exemplo, cita para as plasmazellen os dois typos de reproducção, não resta duvida que a sua divisão se faz geralmente por amitose.

Vejamọs agora, si a descripção das cellulàs do myeloma, mesmo nos casos que receberam a denominação de plasmocytomas, concorda com esse typo de classificação.

Alguns autores limitam-se a classificar as cellulas pelo aspecto que ellas tomam em córtes corados pelos processos communs, sem recorrer aos methodos especificos, ou fazem uma descripção tão superficial, que não é possivel verificar si ellas, de facto, pódem ser incluidas entre as: plasmazellen. (Versé I e II caso.)

Menne, (Virchows Archiv.) que fez um estudo especializado das cellulas do myeloma, dellas faz uma descripção que lembra as cellulas plasmaticas.

Fazendo actuar, sobre as mesmas cellulas, o corante especifico de Pappenheim (verde de methyla-pyronina), comprovou o autor a reacção negativa, excluindo assim as plasmazellen de Unna.

Depois de um longo estudo da fina estructura das cellulas, conclúe: por classifical-as como antecessores agranulados dos myelocytos, isto é, myeloblastos.

O autor é de opinião que os plasmomas devem ser eliminados do grupo dos verdadeiros myelomas.

Mais ou menos do mesmo modo, se pronuncia Permim, (Virchows Archiv.) que, fazendo o estudo das cellulas dos seus tres casos de myeloma, salienta o seu aspecto de cellulas plasmaticas e demonstra, pela figura, a semelhança que ellas têm com as cellulas medullares normaes. Empregando varios methodos de coloração, exclúe as suas cellulas das plasmazellen de Unna-Marchalko, concluindo por classifical-as entre os antecessores agranulados dos myelocytos.

Autores como Abrikosow, Schütz, Dialti, Berblinger, (1.0 e 2. caso) Menne, Martelli, Enochim e Sabolotnou, Tschistowitsch e Kolessnikoff, Carl Hart, Saltikow, Permim (3 casos) Scarlini, Charles e Sanguinetti, etc., classificaram as cellulas dos seus casos de myeloma, entre os myeloblastos. Sobre que base se assenta a opinião dos autores que sustentam o caracter plasmocellular dos seus casos de myeloma?

Martelli, (Le malattie del sangue e degli organi emopojetici) partidario do typo dos plasmomas, abre no seu livro um capitulo especial sob esta denominação, e resume algumas observações.

Referindo-se ao exame microscopico de uma observação de plasmoma, assim se exprime:

"O typo predominante é dado por uma grande cellula mononuclear, com grande nucleo redondo ou ligeiramente oval, geralmente excentrico e de abundante protoplasma homogeneo e, algumas vezes finamente granuloso.

O nucleo é rico de chromatina, que, nas fórmas melhor conservadas, se dispõe claramente em roda de carro; é provido de um ou dois nucleolos, grandes, redondos, intensamente acido-philos e situados quasi sempre no centro, para o qual convergem os raios chromaicos da roda.

Elle acceita todas as côres basicas da anilina e ainda a hematoxylina e o carmim; é, porém, mal e difficultosamente corado pelo verde de methyla, talvez por causa da sua má fixação."

" $N \tilde{a}$ o foi possivel obter bom resultado com a mistura verde methyla pyronina de Pappenheim", "si bem que o protoplasma tomasse uma tinta rosea, porém differente da côr esplendente typica das plasmazellen." 
O autor tambem não obteve uma clara reducção do azul de indo phenol, segundo o methodo da oxydase de Schultze-Sapegno, ficando evidente, apenas, em algumas cellulas, poucos granulos corados em azul.

$\mathrm{Diz}$ o autor que as suas plasmacellulas eram geralmente atypicas (pseudoplasmazellen como elle as denomina.)

Moffatt. - (The Lancet, 1905) descrevendo um caso de plasmoma que elle observou, classifica as cellulas como plasmazellen, porém, confessa que não obteve a reaç̧ão da pyronima e do azul polychromo.

Perry Pepper. -- (Jornal of Medical Research.)

Classifica as cellulas do seu caso de myeloma, como plasmazellen, porque não obteve a reacção da oxydase e nada diz sobre o methodo especifico de Pappenheim.

- Pelos nossos estudos, verificamos a ausencia da zona perinuclear e da reacção de Pappenheim, ao lado de uma pequena differença da estructura nuclear.

Uma séria objecção póde ser "feita.

Si o processo especifico de Pappenheim dá o colorido caracteristico ao protoplasma, dos plasmocytos adultos, o mesmo poderá não acontecer quando actúa sobre as cellulas jovens; immaturas.

Ora, justamente nos seus trabalhos especiaes sobre as plasmazellen, Unna e Sormani põem em fóco a questão determinando, cada um por sua vez, que os plasmocytos jovens, não maduros, adquirem, pelo methodo de Pappenheim, uma côr vermelha muito mais intensa e uniforme do que as cellulas adultas.

Sendo as cellulas do myeloma resultantes de uma intensa proliferação, é logico suppôr que a sua coloração deveria ser muito mais intensa do que normalmente succede com as cellulas da linha lymphatica.

Chegamos, assim, a concluir que, em nosso caso, não se trata de plasmocytoma e que a grande maioria e talvez a totalidade dos casos descriptos na litteratura, sob essa denominação, não póde ser incluida nesse grupo myelomatose problematico.

Resta-nos discutir o myeloblastoma. De accôrdo, aliás, com a maioria dos autores, que classificaram nos seus casos as cellulas identicas á nossas, como myeloblastos, tambem identificamos as nossas cellulas entre estes antecessores dos granulocytos.

E' claro que o nome de myeloblastoma deve ser tomado sob reservas, por isso que os myeloblastos não são absolutamente identicos aos myeloblastos communs qưe entram normalmente na construcção histologica da medulla ossea e, sim, cellulas da série myeloide, brancas, não granulosas e que mostram muita semelhança com as cellulas normaes dessa matriz myeloide. Como nós conseguimòs, o que é muito raro, fazer esfregaços com material fresco, podemos, por isso, dar mais particularidades sobre a estructura das cellulas do myeloma, do que geralmente se encontra na litteratura.

O nucleo no esfregaço, corado pelo Leishmann, mostra nitidamente a estructura caracteristica filamentosa dos nucleos myeloblasticos. (Vide fig. VI.).

Em favor dä classificação das cellulas como myeloblastos, ha ainda a presença frequente de dois e mais nucleolos, a ausencia de uma membrana nuclear bem visivel e a ausencia de granulações azurophilas. 


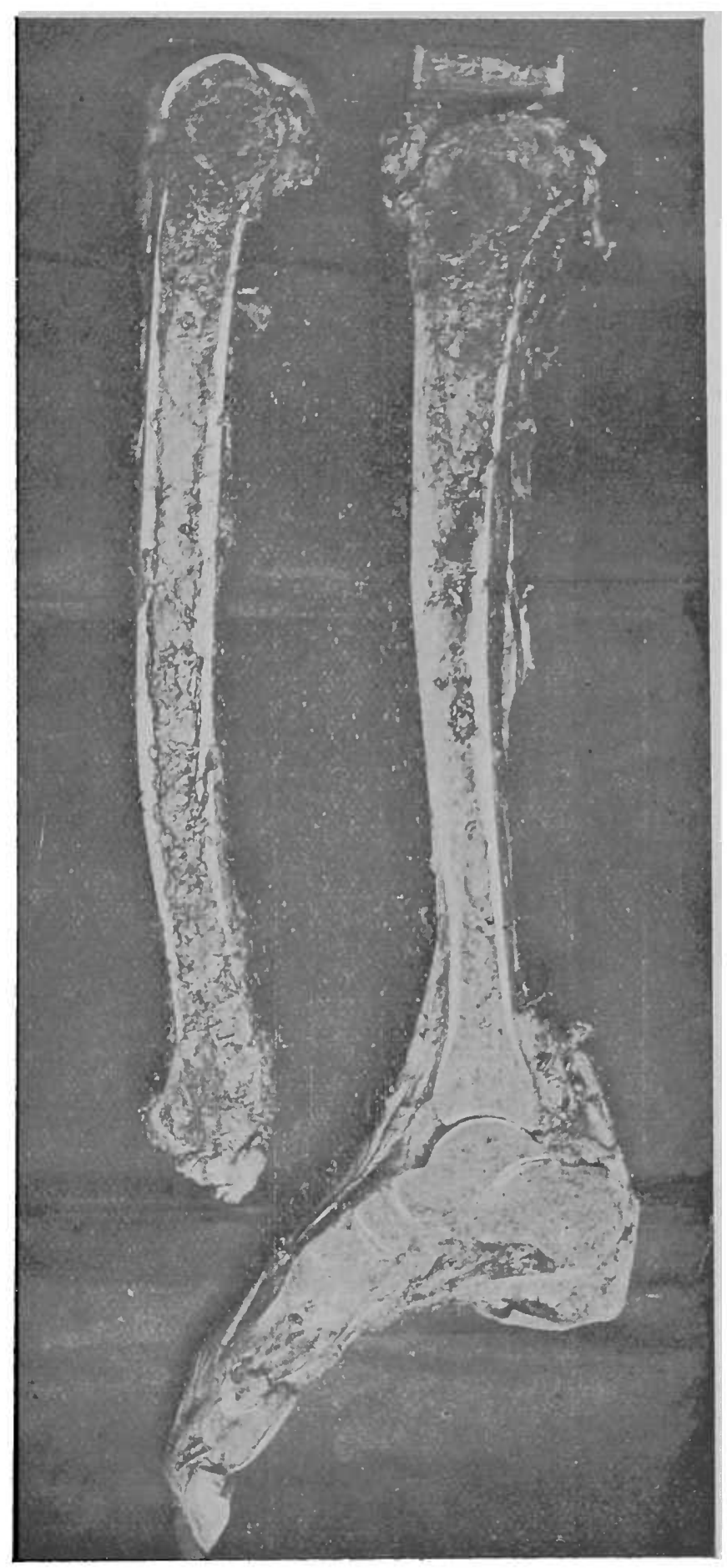

FIG. X

\section{Corte sagittal do femur e da tibia esquerdos}

Observa-se a myelomatose diffusa, substituindo a medulla ossea normal e produzindo a destruição da substancia ossea compacta de dentro para fóra, sobretudo na parte superior. 



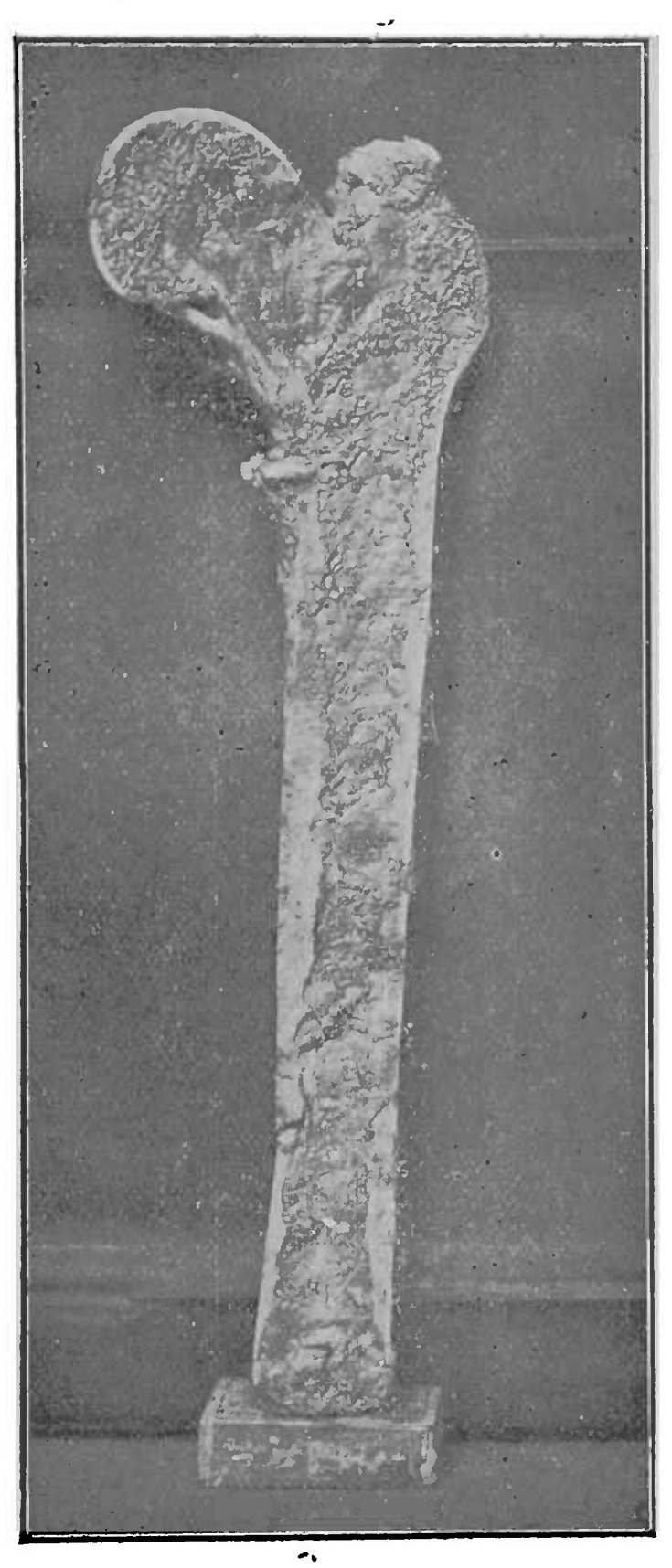

FIG. XI

\section{Corte longitudinal do femur direito amputado}

(Corresponde a radiographia, FIG. II)

Observa-se a myelomatose diffusa, mais accentuada na parte inferior correspondente ao lugar da amputação e na cabeça e collo onde chegou a destruir todo o tecido osseo. 

O unico argumento contrario ao nosso diagnostico microscopico, seria a ausencia da reacção da oxydase, pois é sabido que os myeloblastos geralmente dão a reacção de Schultze (Naegeli e outros autores).

Sobre córtes de myeloma, porém, como já dissemos, alguns pesquisadores - e dos mais illustres - não têm conseguido a reacção positiva, não obstante firmarem por todos os outros caracteres, o seu diagnostico identico ao nosso.

Jogiç, Hirschfeld e Naegeli, autores do maior respeito, publicaram casos de leucemia myeloide, nos quaes não foi possivel obter a reacção da oxydase. Si os myeloblastos pathologicos do tecido circulante (leucemias myeloblasticas agudas). não apresentam a reacção de Schultze, não é de admirar a ausencia desta reacção em casos de myeloma que têm uma evoolução tumoriforme e nos quaes as cellulas myelomatosas são certamente mais pathologicas que as cellulas sanguineas dos estados leucemicos.'

Como a reacção da oxydase é tanto menos sensivel, quanto menos maduras são as cellulas myeloblasticas, é logico que ella não seja obtida em casos - como o nosso, - de formação rapida, precipitada e tumultuosa de cellulas, como prova o decurso clinico relativamente rapido e, ainda mais, as numerosas figuras de mitose, surprehendidas pelo exame microscopico.

Portanto, em casos de myeloma, a ausencia da reacção da oxyđase, não autoriza a exclusão das cellulas do typo myeloblastico, quando ellas, por seus outros caracteres, puderem ser incluidas nesse grupo dos antecessores dos granulocytos.".

O IV Capitulo reservado para as CONSIDERAÇÕES CLINICAS é assin subdividido: 1) Frequencia; 2) Duração; 3) Distribuição geographica; 4) Sexo; 5) Idade; 6) Raça; 7) Profissão; 8) Etiologia ; 9) Symptomas.

Estuda os symptomas geraes (febre, asthenia, anemia, quadro hematologico), os symptomas dependentes do systema osseo (dôr, osteopsathyrosis, deformidades do esqueleto; metastases calcareas, tumores palpaveis e dolorosos) e os dependentes da séde da lesão (apparelho pulmonar, cardio vascular, digestivo, systema nervoso, orgams do sentido).

O Capitulo $V$ intitulado - CONSIDERAÇÕES ANATOMICAS é assim subdividido: Séde, metastases, crescimento, relações com o tecido osseo, forma e volume, côr e consistencia, metamorphoses regressivas e aspecto microscopico.

Reproduzimos o que se refere ao estudo das metastases assim como a primeira parte do VI Capitulo denominada CONSIDERAÇÕES GERAES.

"Mctastases.-Kudrewetsky, Herrich e Hektoen, Parkes Weber, Bechtold, Hoffmann, Christian, Shennan, Schütz, nos seus relatorios, mencionam a existencia de fócos metastaticos em outros orgams (fóra do esqueleto) e, 
entre elles, Perry e Pearce detêm-se longamente no assumpto. Procurando justificar a sụa opinião favoravel á existencia de metastases verdadeiras, reunem varios casos da litteratura, incluido o de Lubarsch que é de parecer contrario e até o de Tchistowitsch e Kolessnikoff que apenas mencionam metastases calcareas!

Quasi todos os autores, porém, são accordes em que as cellulas pathologicas param ante a barreira periostica, transpondo-a sómente nos casos de fractura, de accôrdo com o que tambem verificamos no caso que estamos a estudar.

Seja dito de passagem que, ao exame perfunctorio, é possivel confundir uma forte infiltração parvicellular localizada, (do figado por exemplo) con um supposto fóco metastatico.

Em o nosso caso, (v. g.), o tecido peri-acinoso da glandula hepatica estava invadido pela infiltração parvicellular.

Entretanto, não queremos negar que possam existir verdadeiros fócos myelomatosos nos tecidos extra-medullares, mas não compartilhamos a opinião de que elles resultem de um processo verdadeiramente metastatico. E' mais razoavel suppor que elles se constituam em formações autochtonas, á semelhança do que succede com as multiplas e simultaneas localizações na medullà ossea.

Concorda com esta ultima hypothese a quasi exclusiva electividade do processo para os orgams hematopoeticos.

Lubarsch é do mesmo parecer.

$\mathrm{Na}$ sua polemica com Menne, acceita as idéas deste autor, isto é, que o myeloma não produz metastases e accrescenta que os fócos myeloides extramedullares devem ser considerados como consequencia de uma "molestia systematica."

E lembra ainda que Sternberg demonstrou a presença de myelocytos no baço e nos nodulos lymphaticos e ter Askanazy provado a existencia de fócos sanguineo-formadores no figado.

Contrariando a opinião de Lubarsch, Perry e Pearce citam os casos de Herrich e Hektoen (um fóco no ovario) e de Schütz (um fóco da amygdala direita) que, segundo o seu parecer, só podem ser explicados como formações metastaticas verdadeiras.

A argumentação não é irreprehensivel.

Tratando-se de uma doença systematica do apparelho hematopoetico, muito provavelmente as formações myeloblasticas, myelocyticas, etc., que se encontram fóra do systema gerador do sangue, provém directamente das cellulas do endothelio vascular, como hoje é geralmente admittido para a formação das chamadas metaplasias myeloides.

De facto, sob a acção do estimulo pathologico, pódem-se desenvolver as potencias accumuladas, nas cellulas parieto-vasculares, repetindo-se algumas phases da genese fetal do sangue.

Si quizermos acceitar a hypothese de que o myeloma produz metastases verdadeiras, seremos obrigados a admittir que ellas se processam pela via sanguinea ou pela via lymphatica.

Ora, até o momento actual, não ha demonstrações seguras de existencia de cellulas myelomatosas intravasculares, em periodo anterior ao da constituição dos pseudo-fócos metastaticos.

No terceiro caso de Versé, a invasão do tecido circulante deu-se subfinem, nada havendo de anomal no quadro sanguineo intra-vitam.

No primeiro caso do mesmo autor, diz elle ter encontrado as cellulas anormaes no interior dos vasos venosos e, entretanto, não havia fócos myeloides fóra do esqueleto, concluindo-se dahi que a precipitação intravascular das cellulas anormaes foi causada pelas lesões das paredes vasculares, produzidas poucos momentos antes da morte. 


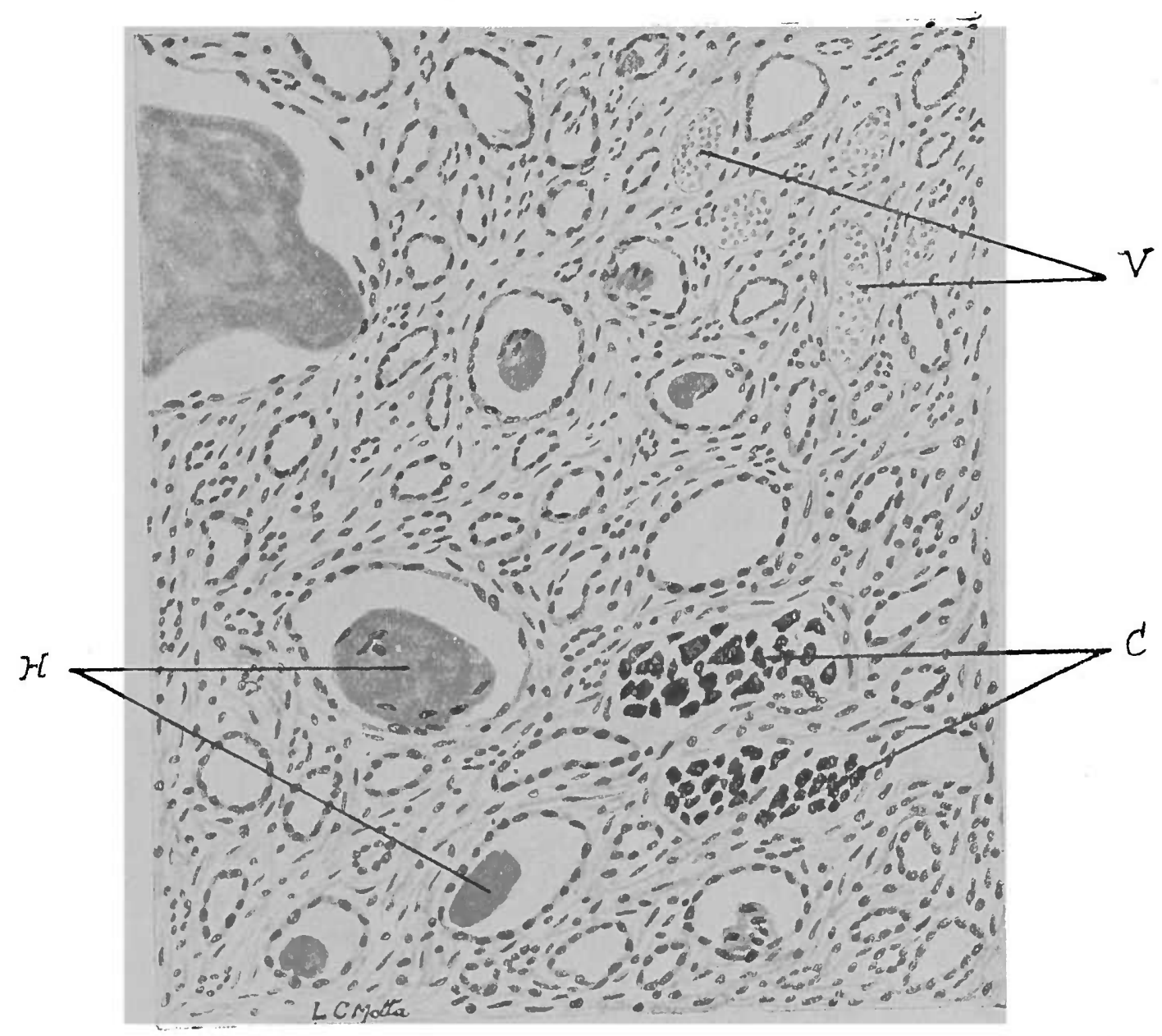

FIG. XII

\section{Metastases calcareas no rim}

1 - Capillares cheios de sangue.

c: - Tubulos uriniferos contendo pequenos blocos calcareos agglomerados.

H - Tubulos uriniferos com cylindros hyalinos. 

Naegeli, para explicar as neoformações myelomatosas extramedullares, formúla uma theoria muito interessante:

Segundo o seu juizo, estes fócos myeloides neoformados surgem por um processo reactivo, que-procura compensar a intensa destruição da medulla ossea normal, facto que tambem se verifica, por exemplo, na destruição accentuada dos ossos, por metastases carcinomatosas."

\section{CAPITULO VI}

\section{CONSIDERAÇÕES GERAES.}

"Os autores ainda não conseguiram chegar a um accôrdo sobre a verdadeirá situação do myeloma entre os varios processos progressivos dos orgams hematopoeticos.

Neste capitulo, discutiremos a questão, procurando resolvel-a de conformidade com os estudos mais modernos que se têm feito sobre o assumpto.

Começaremos por eliminar os processos regenerativo e inflammatorio.

O primeiro, não só porque a proliferação myeloide não succede a nenhuma necessidade anterior de regeneração, como tambem pelo excessivo desenvolvimento do processo anormal.

O segundo, por varias causas que convém especificar: uniformidade do typo cellular, ausencia das cellulas inflammatorias, evolução progressiva que não termina pela restitutio ad integrum, nem pela organização, continuando, ao contrario, o tecido neoformado a crescer indefinidamente.

Podemos incluir o myeloma entre os processos blastomatosos?

- Quasi todos os autores (Kaufmann, Barbacci, Borst (Aschoff), Schmidt (Aschoff), Schridde (Aschoff), Achard e Loeper, Letulle e Nattan Larrier, Ribbert, Hermann e Morel, Schmauss) classificam o myeloma entre os blastomas.

Varios delles, e dos mais conspicuos e modernos, deixam, porém, entrevêr a duvida.

Assim diz Barbacci: "o caracter hyperplastico da neoformação é muito visivel e muito provavelmente todo o processo morbido representa uma fórma myelogenica da pseudo-leucemia."

Martelli estabelece uma classe especial para os casos duvidosos, intitulada hemosarcoses, comprehendendo as leucemias, pseudo-leucemias, lymphosarcomatose, myeloma, chloroma, etc.

Schmidt e outros falam de molestia systematica. Algumas razões, innegavelmente, militam a favor do conceito de uma neoformação blastomatosa, principalmente a uniformidade do typo cellular, o limite circumscripto, a autonomia e a continuidade incessante do crescimento.

Entretanto, contra a inclusão do myeloma entre os processos blastomatosos, ha varios e poderosos argumentos.

Contra a' sua inclusão entre os tumores malignos, temos que salientar o pequeno polymorphismo das cellulas que o compõem e a falta de metastases verdadeiras.

Em favor da hypothese de se tratar de um tumor maligno, temos o seu rapido crescimento, a falta de limite capsular e a consequencia letal infallivel.

Faltam todavia os caracteres indispensaveis para a diagnose certa de tumor maligno: polymorphismo accentuado das cellulas e crescimento infiltrativo, mesmo querendo admittir a existencia de metastases que, como já dissemos, não são verdadeiras. 
Podemos considerar o myeloma como pertencente ao grupo dos tumores benignos? Seguramente, não.

Ha varias razóes que o exclúem completamente desse grupo:

1) a sua grande riqueza cellular, jámais encontrada em tumores benignos de origem mesenchymal.

2) a sua multiplicidade accentuada, quasi nunca observada nos tumores benignos.

Re::ordamo-nos apenas que a molestia de Recklinghausen apresenta-se com esse caracter de grande multiplicidade, sendo muito numerosos os tumores benignos.

Aliás, esta molestia, como o myeloma, não está perfeitamente classificada.

O mal de Recklinghausen, porém, apesar de ser mortal, só tem esse exito depois de muitos decennios.

3) o seu apparecimento tardio. Os blastomas benignos multiplos săo sempre congenitos e apparecem nos dois primeiros decennios da vida, ao contrario de myeloma, que se manifesta geralmente no quarto e quirto decennio.

Por simples exclusão, ficam-nos apenas a considerar as hyperplasias e naturalmente em primeiro logar, pelo seu grande desenvolvimento, as hyperplasias leucemicas e, sobretudo, no caso particular, as hyperplasias pseudo-leucemicas.

$\mathrm{O}$ apparecimento, a priori, em fócos multiplos simultaneos, independentes e a diffusão completa 'do processo morbido, approximaram-n'o muito naturalmente das hyperplasias systematicas.

As leucemias lymphaticas, por exemplo, apresentam os mesmos pontos de contacto com os blastomas, sem que, por isto, sejam incluidas entre os processos blastomatosos verdadeiros. O myeloma, pelo seu comportamento, póde, em parte, ser posto em parallelo, com a lymphadenose aleucemica. Esta tambem começa por hyperplasias tumoriformes (lymphaticas) circum-. scriptas que crescem quasi continuamente, porém, sempre vagarosamente, atravéz de varios annos; não ha geralmente grandes alterações do quadro hematologico; sendo porém, possivel uma transição para a leucemia lymphatica verdadeira, facto aliás raramente observado.

Do mesmo modo que no myeloma, na lymphadenose alencemica ha uniformidade do typo cellular e geralmente producção de cellulas não maduras.

Si é verdade que na lymphadenose aleucemica, ao menos em certos casos, ha formação de $1 \mathrm{~m}$ quadro sanguineo quasi leucemico, (facto não observado nos myelomas) a explicação pódé ser encontrada na grande differença de duração desses dois processos morbidos. Realmente a lymphadenose aleucemica persiste durante muitos annos, ás vezes sem produzir symptomas sérios e mesmo depois que estes. se manifestam,' geralmente só sobrevem a morte depois de um tempo muito prolongado (até 20 annos em total).

Ao contrario, o myeloma, pela sua localização na medulla ossea, causa lesões de muito maior importancia e por isso tem exito letal em tempo muito menos dilatado (em média um anno, a um anno e meio) não permittindo, portanto, o desenvolvimento de um quadro hematologico pseudo-leucemico ou leucemico.

De facto, como já vimos, o myeloma causa a destruição dos ossos do. esqueleto, facilitando as fracturas e consecutiva immobilidade mais ou menos completa dos doentes e a devastação quasi total da medulla ossea vermelha, certamente de maior importancia vital do que os glanglios lymphaticos.

Entretanto, na lymphadenose aleucemica mesmo incipiente, podemos encontrar no sangue peripherico uma lymphocytose ás vezes muito accentuada (ainda que näo haja augmento total dos globulos brancos) ao plasso que, na grande maioria dos casos de myeloma, verifica-se apenas uma 


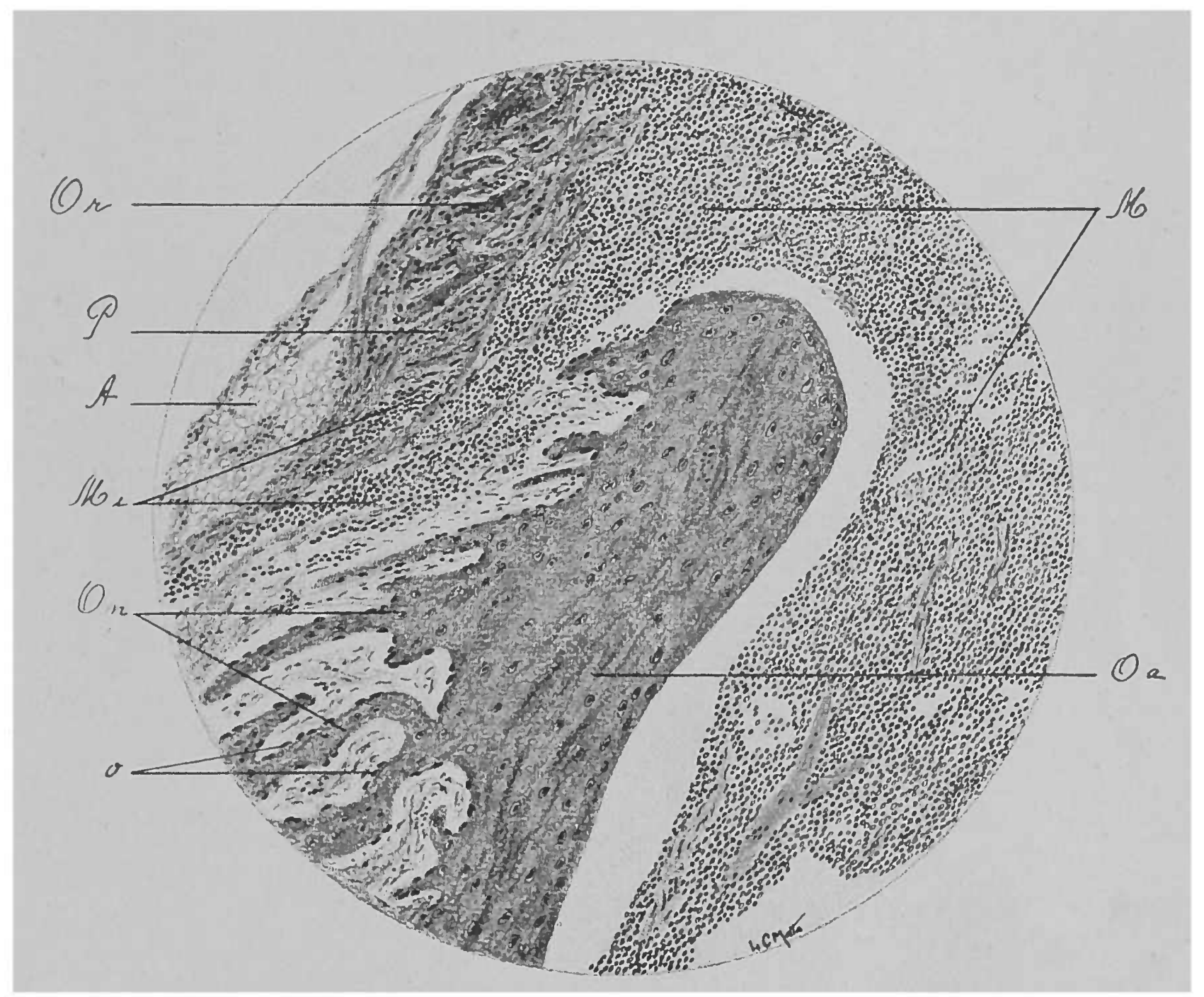

FIG. XIII

\section{Corte histologico do collo do femur (myeloma)}
$O a$ - Osso antigo
Or - Restos osseos isolados
$O n$ - Osso neoformado
$O$ - Osteoblastos

$P$ - Periosteo

$A$ - Cellulas adiposas

$M$ - Myeloma

$M i$ - Myeloma invasor 

anemia mais ou menos profunda e não a invasão myeloblastica no sangue circulante.

Este contraste, entre os dois processos morbidos, que apparentemente parece não permittir a inclusão do myeloma entre as doenças aleucemicas (myelose aleucemica) póde ser perfeitamente explicado.

E' innegavel que a penetração dos elementos lymphocyticos no sangue peripherico dá-se muito mais facilmente do que a dos elementos myelocytarios.

E' sufficiente considerar as numerosas molestias e processos pathologicos, nos quaes ha uma lymphocytose muito accentuada e que não pódem ser incluidos entre os processos leucemicos verdadeiros.

Os globulos da série lymphatica penetram com mais facilidade no sangue peripherico, talvez porque os ganglios lymphaticos estão em directa communicação com o sangue circulante pelos vasos lymphaticos; os elementos da linha myeloide têm apenas uma communicação indirecta, porque passam ao sangue atravéz dos capillares da medulla ossea.

Eliminado este argumento, desfavoravel á inclusão do myeloma entre as hyperplasias leucemicas, surge um outro: a uniformidade do typo cellular.

Si é verdade que nas leucemias lymphaticas o quadro histologico dos processos leucemicos é uniforme, não é menos certo que nas leucemias myeloides encontramos sempre, na medulla ossea, um aspecto cytologico variado, entrando na composição do tecido neo-formado, myeloblastos, promyelocytos e myelocytos e nunca um unico typo cellular.

Ora, o myeloma é quasi sempre constituido pela proliferação de um unico typo de cellula.

Apenas no $30^{\circ}$ caso de Versé, entravam diversas cellulas pathologicas, na composição da neo-formação medullar.

Isto quer dizer que as cellulas se detêm nos primeiros estadios do seu desenvolvimento (myeloblasto, na maioria dos casos) e só raramente, como no terceiro caso de Versé, ellas attingem maior gráu de maturidade.

Talvez até, este ultimo facto explique a penetração das cellulas myelomatosas no sangue circulante, observado no caso de V'ersé, como phenomeno sub-final.

Do que fica exposto, conclue-se que o myeloma não póde sẹr perfeitamente incluido em qualquer dos processos morbidos, bem caracterizados e bem determinados.

Entretanto, podemos affirmar que o myeloma deve ser considerado como um processo systematico do apparelho hematopoetico, constituindo evidentemente um processo pathologico, sui generis, porém bastante semejhante aos processos tumoriformes aleucemicos."

Termina o A. o VI capitulo fazendo o diagnostico differencial com os blastomas, kystos osseos, granulomas infecciosos, osteopsathyroses - osteoporose senil, osteomalacia, osteite deformante progressiva de Paget.

Resume o A. os principaes caracteres do myeloma:

“- 1) Apparecimento sob a fórma multipla simultanea ou mais raramente sob a fórma diffusa, com invasão de quasi todos os ossos do esqueleto.

- 2) Predilecção accentuada do processo pathologico para se assestar nos ossos chatos e, por ordem decrescente de frequencia, nos ossos curtos e longos. 
leto.

-. 3) Frequencia de fracturas espontaneas e de deformidades do esque-

- 4) Algumas vezes, formação de tumores palpaveis e dolorosos.

-- 5) Duração média de um anno a um anno e meio.

-6) Preferencia notavel para os individuos do sexo masculino, cuja idade está geralmente comprehendida entre 40 e 60 annos.

- 7) Apparecimento na urina do corpo albuminoso thermo-soluvel $d n$ Bence-Jones.

- 8) Imagem radiographica, demonstrando um processo da rarefacção ossea ás vezes com apposição de tecido osseo neoformado.

- 9) Manifestações dolorosas que apparecem por intervallos mais ou menos variaveis. logico.

- 10) Anemia progressiva sem notavel alteração do quadro hemato-

- 11) Quasi sempre, concomitancia de phenomenos pulmonares e nervosos.

- 12) Asthenia.

De todos os symptomas o mais caracteristico é a albumosuria de BenceJones.

Todavia a presença na urina do corpo albuminoso thermo-soluvel (reacção de Bence-Jones) não é uim signal absolutamente pathognomonico do myeloma.

Schmidt (Aschoff), por exemplo, diz que a reacção póde ser positiva em "outras molestias multiplas da medulla ossea."

Kaufmann assignala que a albumose thermo-soluvel póde ser encontrada na urina de doentes de leucemia lymphatica e nós já fizemos referencia ás verificações semelhants de Askanazy e Decastello.

Hirschfeld; no seu recente trabalho sobre o myeloma; cita alguns autores que affirmaram sêr positiva a reacção de Bence-Jones na urina de individuos que não soffriam da doença de Rustizky-Kahler.

Por outro lado, algumas (raras) vezes a reacção é negativa mesmo em casos de myeloma."

\section{FINALMENTE EIS AS CONCLUSÕES DO A.}

"I. - A doença de Rustizky-Kahler deve ser considerada como um processo morbido systematico do apparelho hematopoetico, constituindo um processo patholgico "sui generis", porém, bastante semelhante aos processos tumoriformes aleucemicos; muito provavelmente não se trata de um blastoma verdadeiro.

I. - E' uma doença da idade adulta e apparece sobretudo entre os 40 e 60 annos; excepcionalmente, porém, como no nosso caso (22 annos), pódle verificar-se em individuos de mais baixa idade.

III. - Tem accentuada preferencia para os individuos do sexo masculino.

IV. - Apresenta-se em geral sob a fórma multipla circumscripta e mais raramente, como no nosso doente, sob a fórma diffusa.

- V. - Tem sua séde primaria e preferida, na medulla ossea.

VI.-Assesta-se de preferencia nos ossos chatos e por ordem decrescente de frequencia nos ossos curtos e longos.

VII. - A destruição do tecido osseo faz-se por um processo que corresponde ao denominado de atrophia liza; em geral o periosteo é respeitado.

VIII. - Procurando compensar em parte a destruição do ossó, ás viezes, ha uma pequena appossição de tecido osseo neoformado de origem periosta! (osteophyto). 


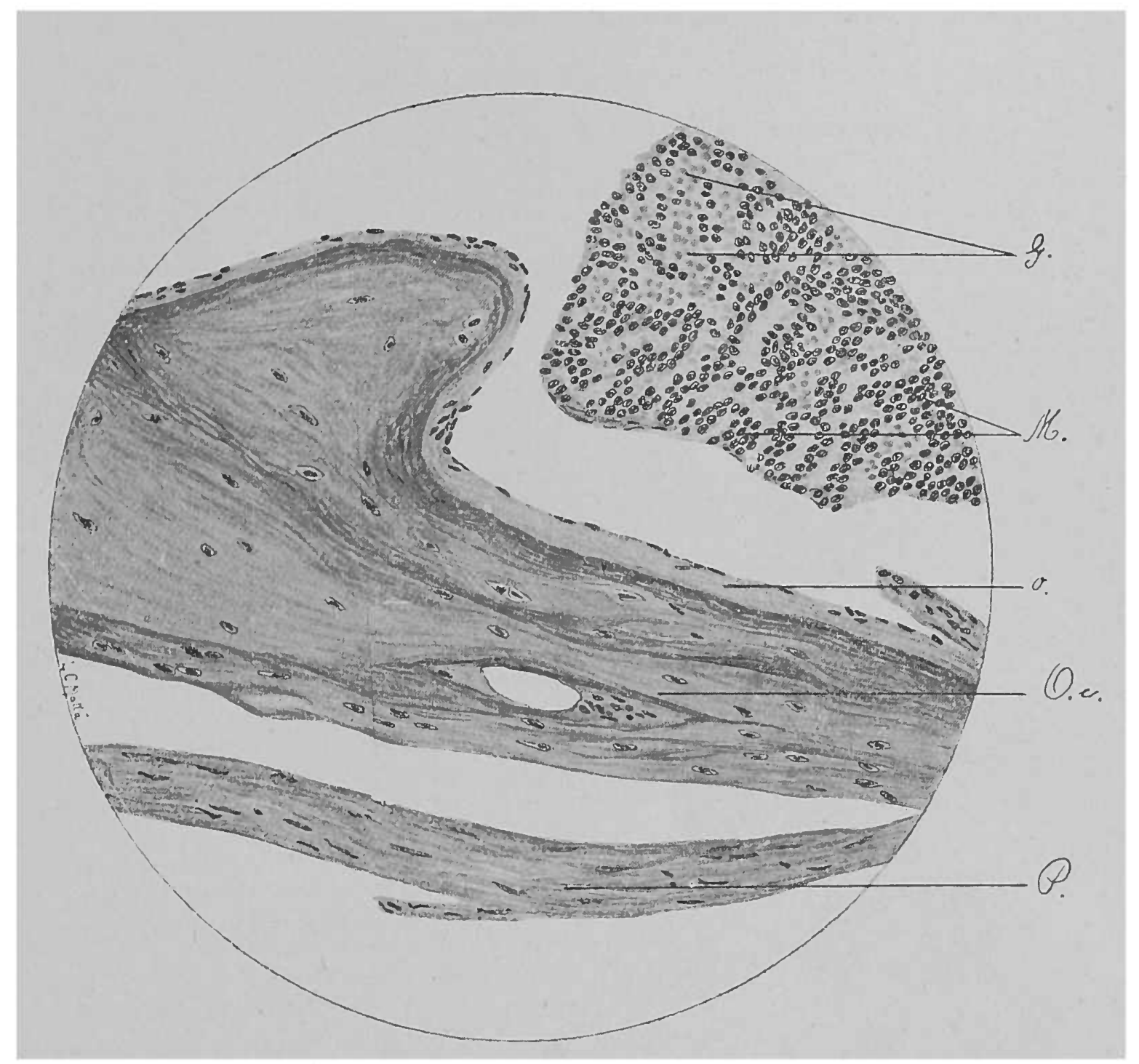

FIG. XIV

\section{Corte histologico da tibia (myeloma)}

Augmento grande

$G$ - Globulos vermelhos de mixtura com as cellulas myelomatosas.

$M$ - Cellulas do myeloma.

$o$ - Orla osteoide.

Oc-Osso compacto.

$P$ - Periosteo. 

IX. - São frequentes as fracturas eśpontaneas e as deformidades do esqueleto.

X. - São frequentes as metastases calcareas.

XI. - Não ha producção de metastases verdadeiras como nos blastomas e os fócos extramedullares, quando existem, constituem formações autochtonas.

XII. - Na quasi totalidade dos casos, o tecido myelomatoso neoformado é composto de um unico typo cellular.

XIII. - Esse typo cellular é quasi sempre representado pelos antecessores agranulados dos granulocytos.

XIV. - A totalidade, talvez, đos casos descriptos na litteratura, sob a denominação de plasmocytomas - não deve ser incluida nesse grupo problematico dos myelomas.

XV. - A coloração especifica de Pappenheim, para as plasmazellen de Unna-Marchalko, permitte differençar estas cellulas de outras, muito semelhantes.

XVI. - Em o nosso caso, as cellulas dos myelomas, que apresentavam, pelas colorações communs, muitos dos caracteres das cellulas plasmaticas, não tomaram o colorido especifico, sob a acção do verde de methyla-pyronina.

XVII. - A ausencia da reacção da oxydase não autoriza a exclusão diagnostica das cellulas brancas da linha myeloide, quando os outros caracteres permittam a sua identificação; Jogiç, Hirschfeld e Naegeli não obtiveram sempre a reacção do indophenol, mesmo em casos authenticos de leucemia myeloide.

XVIII. - Na doença de Rustizky-Kahler é quasi constante a presença, na urina, de um corpo albuminoso thermo-soluvel (reacção de Bence-Jones). Esta reacção foi sempre constante no nosso caso.

XIX. - Durante a evolução da doença, ha manifestações dolorosas que apparecem com intermittencias irregulares.

XX. - Manifestam-se ainda por ordem crescente de frequencia, phenomenos renaes, pulmonares, nervosos, 'digestivos, circulatorios.

XXI. -Quasi sempre, ha uma anemia progressiva, sem notavel alteração do quadro hematologico.

XXII. - Em média, a duração do processo myelomatoso é de um anno, a um anno e meio.

XXIII. - O seu prognostico é letal.

XXIV. - Até o momento actual, não ha tratamento algum para a doença de Rustizky-Kahler.

\title{
A proposito de um caso de uréthrorrhaphia circular
}

\author{
pelo Dr. Zephirino do Hmaral
}

(assistente de clinica cirurgica da Faculdade de Medicina e Cirurgia de S. Paulo)

Nas operações praticadas na urethra, é de regra applicarmos uma sonda de demóra no canal, para proteger a ferida operatoria do contacto da urina; porém na maioria dos casos, a derivação da urina pela sonda de permanencia na urethra não satisfaz o nosso "desideratum". Assim é que, não raras vezes, numa simples sutura de uma 